\title{
Organization of the Mammalian Locomotor CPG: Review of Computational Model and Circuit Architectures Based on Genetically Identified Spinal Interneurons
}

\author{
(Dllya A. Rybak, Kimberly J. Dougherty, and Natalia A. Shevtsova
}

DOI:http://dx.doi.org/10.1523/ENEURO.0069-15.2015

Department of Neurobiology and Anatomy, Drexel University College of Medicine, Philadelphia, Pennsylvania 19129

\begin{abstract}
The organization of neural circuits that form the locomotor central pattern generator (CPG) and provide flexor-extensor and left-right coordination of neuronal activity remains largely unknown. However, significant progress has been made in the molecular/genetic identification of several types of spinal interneurons, including $\mathrm{VO}_{\mathrm{O}}\left(\mathrm{VO}_{\mathrm{D}}\right.$ and $\mathrm{V} \mathrm{O}_{\mathrm{V}}$ subtypes), $\mathrm{V} 1, \mathrm{~V} 2 \mathrm{a}, \mathrm{V} 2 \mathrm{~b}$, V3, and Shox2, among others. The possible functional roles of these interneurons can be suggested from changes in the locomotor pattern generated in mutant mice lacking particular neuron types. Computational modeling of spinal circuits may complement these studies by bringing together data from different experimental studies and proposing the possible connectivity of these interneurons that may define rhythm generation, flexor-extensor interactions on each side of the cord, and commissural interactions between left and right circuits. This review focuses on the analysis of potential architectures of spinal circuits that can reproduce recent results and suggest common explanations for a series of experimental data on genetically identified spinal interneurons, including the consequences of their genetic ablation, and provides important insights into the organization of the spinal CPG and neural control of locomotion.
\end{abstract}

Key words: central pattern generator; computational modeling; flexor-extensor coordination; genetically identified neurons; left-right coordination; locomotion; spinal cord

\section{Significance Statement}

We review and analyze together (1) the currently proposed architectures of the central pattern generator (CPG) in the mammalian spinal cord and (2) different classes of genetically identified spinal interneurons. We suggest the possible roles of these interneurons, and their connectivity and functions within the spinal circuitry and the CPG, which can simultaneously explain multiple experimental data and provide important insights into the organization and operation of neural circuits in the spinal cord during locomotion.

Received June 23, 2015; accepted August 29, 2015; First published September 8, 2015.

The authors declare no competing financial interests.

Author Contributions: I.A.R., K.J.D., and N.A.S. designed research; I.A.R., K.J.D., and N.A.S. performed research; I.A.R., K.J.D., and N.A.S. wrote the paper.

This study was supported by National Institutes of Health Grants NS081713 and NS090919 to I.A.R.; and NS095366 to K.J.D.

Correspondence should be addressed to Dr. Ilya A. Rybak, Department of Neurobiology and Anatomy, Drexel University College of Medicine, 2900 Queen Lane, Philadelphia, PA 19129. E-mail: rybak@drexel.edu.

DOI:http://dx.doi.org/10.1523/ENEURO.0069-15.2015

Copyright (C) 2015 Rybak et al.

This is an open-access article distributed under the terms of the Creative Commons Attribution 4.0 International, which permits unrestricted use, distribution and reproduction in any medium provided that the original work is properly attributed. 


\section{Introduction}

The nervous systems of vertebrates contain neural networks representing central pattern generators (CPGs) that generate neural oscillations and control rhythmic movements. These CPGs are involved in many important functions, including different forms of locomotion, such as swimming, walking, running, and flying. Interplay between modeling and experimental studies has been valuable in advancing our understandings of different vertebrate CPGs (Lansner et al., 1998; ljspeert, 2001; Grillner, 2006; Rybak et al., 2006a,b; Grillner et al., 2007; McCrea and Rybak, 2008; Wolf et al., 2009; Zhong et al., 2012; for review, see Rybak, 2014). Computational modeling provides powerful tools through which experimental findings and current hypotheses from different laboratories can be incorporated together in a common computational framework allowing the generation of plausible predictions for future experimental studies. In this review, we focus on the mammalian locomotor CPG, and merge recent experimental and computational findings to produce a more complete common framework.

The vertebrate locomotor CPGs are located in the spinal cord. The first schematic of the locomotor CPG, called the "half-center" model, was proposed by Graham Brown (1914) and elaborated on by Lundberg (1981; for review, see McCrea and Rybak, 2008; Stuart and Hultborn, 2008). This model included two (flexor and extensor) half-centers reciprocally inhibiting each other. The mutual inhibitory interactions between the half-centers were mediated by inhibitory interneurons that ensured that only one halfcenter could be active at a time. The activity of the active half-center gradually reduced due to some fatigue or adaptation mechanism, leading to the activation of the antagonistic half-center. The antagonistic half-center then inhibited the active half-center, hence switching the locomotor phase. It was suggested that the flexor and extensor half-centers directly project to and activate the flexor and extensor motoneurons, respectively. Studies on the immobilized decerebrate cat demonstrated that continuous electrical stimulation of the midbrain locomotor region (MLR) can produce "fictive locomotion"- the rhythmic pattern of motoneuron activity that is characterized by alternating activation of flexor and extensor motoneurons similar to that observed during normal locomotion in the intact animal (Rossignol, 1996; Markin et al., 2012). A similar pattern of locomotor activity can also be produced by systemic administration of the noradrenergic precursor, L-DOPA (Jankowska et al., 1967a,b). The demonstration that both MLR stimulation and neuroactive drug application can evoke fictive locomotion provided strong evidence for the existence of locomotor CPG in the mammalian spinal cord.

In contrast to many other neural networks in the brain, whose architecture, neuron types, and connectivity have been mainly or partly determined, the spinal cord circuitry does not exhibit a clear spatial organization, which makes it difficult to distinguish network elements with specific functions using traditional electrophysiological methods in order to reconstruct and suggest a realistic circuit organization from these data. Significant progress in this direction has been recently achieved due to the identification of several types of spinal interneurons during development based on the expression of transcription factors and the use of isolated spinal cord preparations from genetically modified mice lacking particular neuron types (Jessell, 2000; Lanuza et al., 2004; Gosgnach et al., 2006; Kiehn, 2006, 2011; Zhang et al., 2008, 2014; Goulding, 2009; Gosgnach, 2011; Kiehn, 2011; Kiehn and Dougherty, 2013; Talpalar et al., 2013).

To date, a series of spinal interneurons has been genetically identified and functionally characterized using these approaches. At the same time, the exact functional roles of these neurons remain purely understood, and their possible location, connectivity, and functions within the currently considered computational architectures of spinal and CPG circuits have not been considered and analyzed so far. In this review, we have made an attempt to include these neurons, and their potential interactions and functions, in a common logical and computational framework to propose explanations for multiple experimental data and provide important insights into the organization and operation of neural circuits in the spinal cord during locomotion.

\section{Models of the locomotor CPG}

The classical half-center concept initially proposed by Graham Brown and Lundberg represents only a general, simplified CPG organization and cannot reproduce and explain many features of the real locomotor pattern generated in the mammalian spinal cord. The actual locomotor pattern does not exhibit strictly alternating flexor and extensor activities with all motoneurons clearly belonging to one of these two groups. The real pattern is more complicated and includes motoneuron pools (e.g., the ones controlling biarticular muscles) that exhibit bursts in each locomotor phase or only a very short burst within one phase. There are also noticeable differences in the timing of burst onset and/or offset between different flexor and/or between different extensor motor pools. To overcome these and other limitations of the classical half-center model, Grillner (1981) proposed a unit burst generator (UBG) concept of CPG organization that suggested the existence of several separate rhythmogenic modules (or unit burst generators) controlling each joint of the limb and interacting with each other as coupled neural oscillators. The other solution, proposed by Rybak et al. (2006a,b) and McCrea and Rybak (2007, 2008), suggested that the spinal CPG has a two-level functional organization consisting of a bipartite half-center rhythm generator (RG) and pattern formation (PF) circuits (Fig. $1 A, B)$. In this organization, the PF circuits mediate RG control of motoneuron activity and distribute RG activity to functionally distinct populations of interneurons projecting to groups of synergist motoneuron pools. The motoneuron pools controlled by a common source at the PF level display a synchronized activity and represent motor synergies controlled by the CPG. During locomotion, these synergies may be refined by both descending signals from higher centers and peripheral afferent feedback. The potential advantages and disadvantages, and 


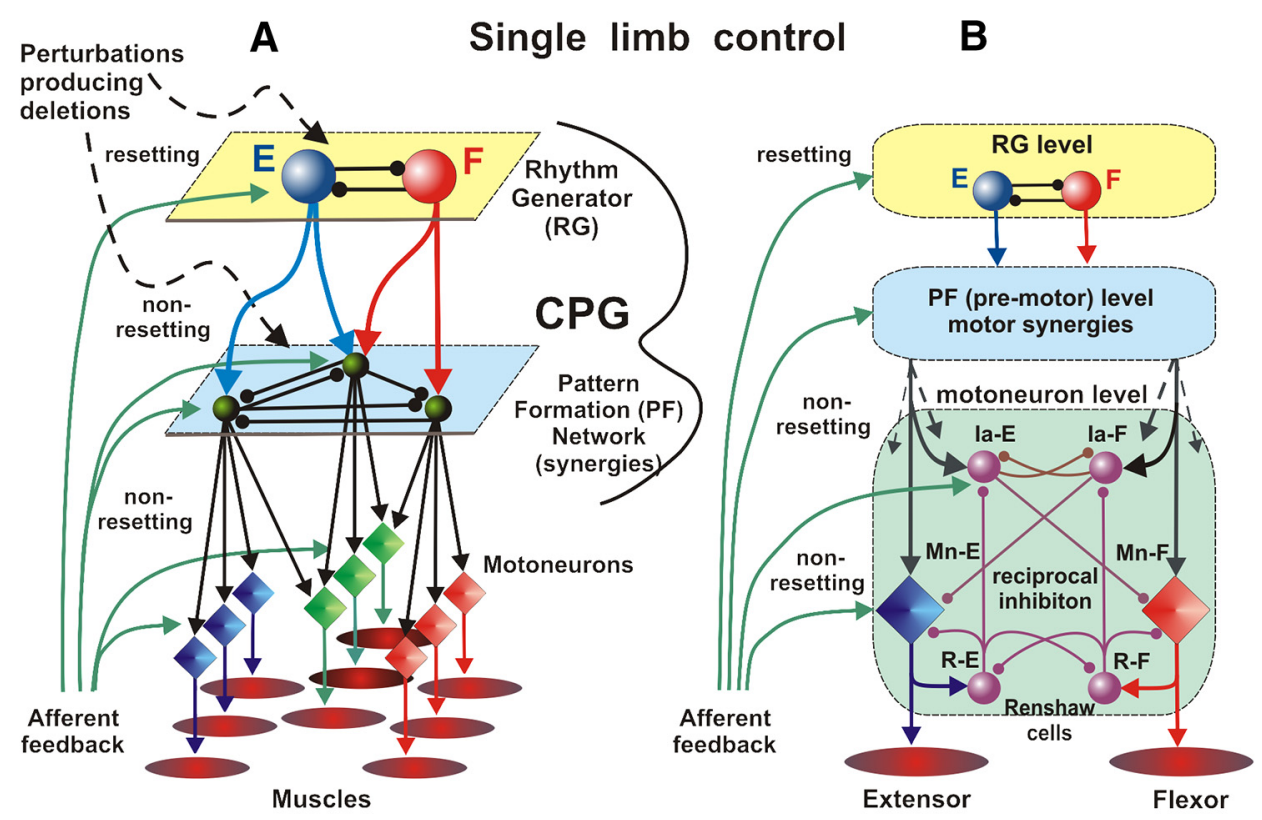

C Bilateral left-right interactions

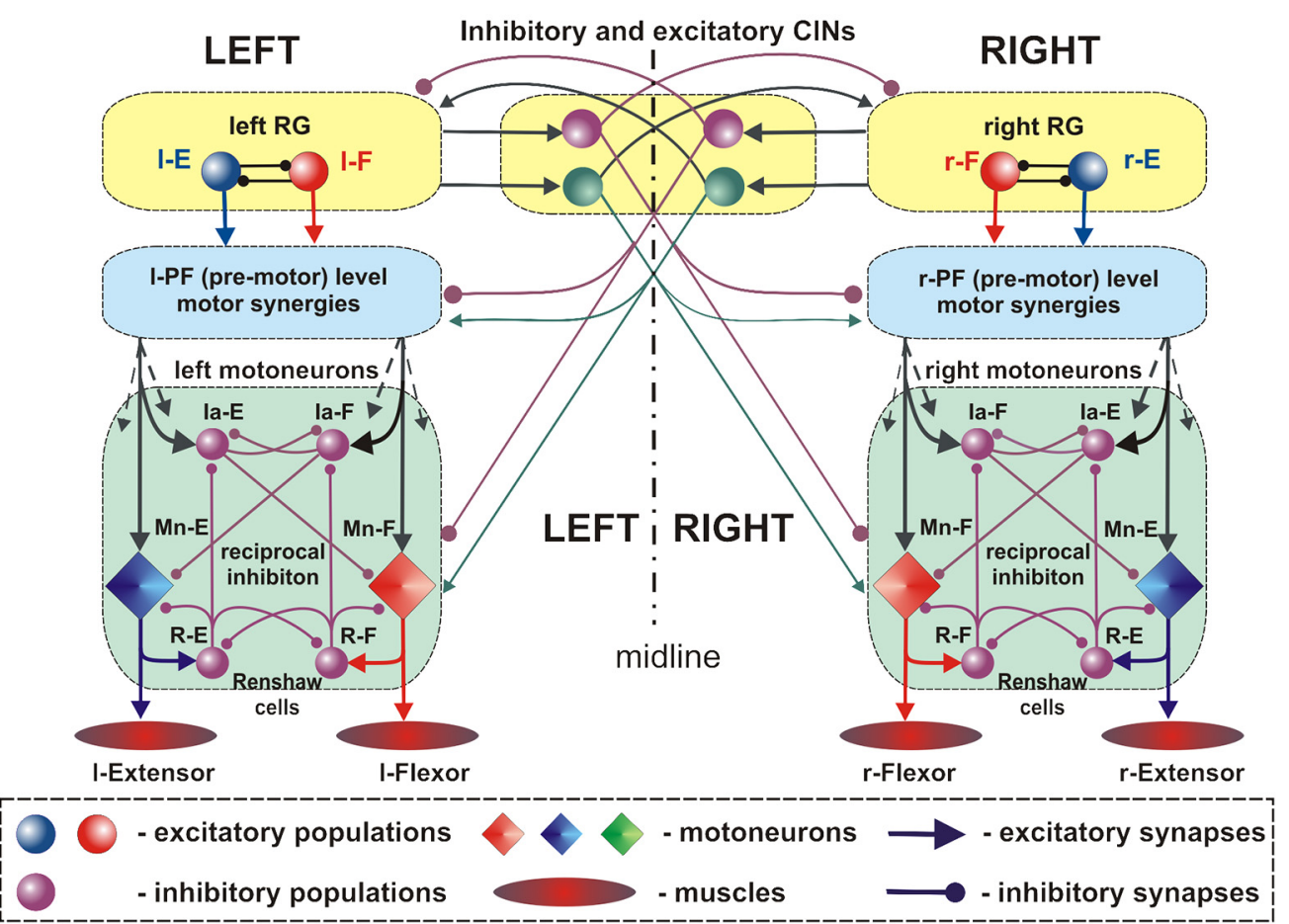

Figure 1. Two-level model of locomotor CPG and left-right commissural interactions. $\boldsymbol{A}, \mathrm{A}$ two-level functional organization is suggested to include bipartite half-center RG and PF circuits that mediate RG control of motoneuron activity and distribute RG inputs to functionally synergist motoneuron pools. Different perturbations and afferent stimuli affecting the system at the RG level may reset the rhythm (produce resetting deletions), whereas perturbations and afferent signals acting at the PF or motoneuron level cannot reset the rhythm and can only produce non-resetting deletions. $\boldsymbol{B}$, Organization of interactions at the lower, motoneuron level, including flexor and extensor motoneurons (Mn), la interneurons, and Renshaw cells (R). $\boldsymbol{C}$, Organization of bilateral left-right interactions in the spinal cord mediated by inhibitory and excitatory CINs. E, Extensor; F, flexor; I, left; r, right.

the plausibility of the UBG and two-level concepts are still debated in the literature (McCrea and Rybak, 2008; Stuart and Hultborn, 2008; Zhong et al., 2012; Hägglund et al., 2013; Wiggin et al., 2012; Grillner and Manira, 2015;
McLean and Dougherty, 2015). Independent of CPG organization, there is also a lower motoneuron level in the spinal cord that contains multiple circuits of local reflexes defined by special interactions between the populations 
of particular motoneurons, Renshaw cells, and interneurons involved in nonreciprocal and reciprocal antagonist interactions and processing of afferent feedback (la, lb, and other types; Fig. 1B). In the framework of a multilevel CPG, any spontaneous perturbation or an afferent or supraspinal signal affecting spinal circuitry below the RG level (i.e., at the PF or motoneuron levels) may produce a non-resetting deletion (i.e., the omission of one or more bursts in the output motor activity) or may cause a delay or earlier onset of the next burst without a general phase shift in the post-perturbation or post-deletion rhythm relative to the pre-perturbation or pre-deletion rhythm (i.e., without rhythm resetting). Resetting perturbations and deletions can only happen at the RG level (Rybak et al., 2006a,b; McCrea and Rybak, 2007, 2008; Zhong et al., 2012; Fig. $1 A, B$ ). Therefore, the analysis of burst deletions in the activity of different spinal neurons may suggest the level of their operation.

It is generally accepted that in limbed vertebrates, including mammals, there is a separate CPG controlling each limb, whose rhythmic movements are coordinated with the movements of other limbs via neural pathways within the cord and supraspinal and afferent signals (Grillner, 1981, 2006; Orlovsky et al., 1999; McCrea and Rybak, 2008). Specifically, the left-right limb coordination is mediated by inhibitory and excitatory commissural interneurons (CINs), whose axons cross the midline and affect neurons located in the contralateral side of the cord (Kjaerulff and Kiehn, 1997; Butt and Kiehn, 2003; Kiehn and Butt, 2003; Lanuza et al., 2004; Quinlan and Kiehn, 2007; Jankowska, 2008; Kiehn, 2011; Talpalar et al., 2013). The identified CINs were shown to provide inhibitory and excitatory synaptic inputs to contralateral motoneurons (Butt and Kiehn, 2003; Kiehn and Butt, 2003; Quinlan and Kiehn, 2007). However, the effects of synaptic inputs from the CINs to contralateral motoneurons are supposed to be weaker than the effects of inputs that these motoneurons receive from the ipsilateral CPG, so that under normal conditions the contralateral signals do not override the ipsilateral drives to the corresponding motoneurons. To coordinate left and right rhythmic activities (e.g., alternate or synchronize them), CINs should not only project to contralateral motoneurons, but should primarily mediate mutual interactions between the left and right rhythm generators (Fig. 1C). The effects of the CINs on either RG interneurons or motoneurons cannot be significant since the genetic ablation or silencing of CINs (e.g., V0 and V3 types) did not exhibit obvious changes in the frequency or amplitude of locomotor activity recorded from ventral roots, even when left-right alternation of activity was changed to left-right synchrony (Lanuza et al., 2004; Zhang et al., 2008; Talpalar et al., 2013). This means that, although left-right interactions mediated by inhibitory and excitatory CINs do not affect the amplitude and frequency of locomotor oscillations, they are sufficient to coordinate phase relationships between rhythmic activities generated by left and right RGs, and hence to define the gait of locomotion.

\section{Spinal interneurons identified from developmental and genetic studies}

Over the past decade, a novel experimental approach incorporating genetic and molecular techniques enabled the determination of key neural elements of the spinal circuits and locomotor CPG (Jessell, 2000; Goulding, 2009). Molecular genetic experiments have shown that the developing neural tube in the embryonic mouse can be divided into distinct populations of spinal neurons based on the expression of transcription factors. Specifically, transcription factors were used to identify several classes of ventral horn interneurons, including V0-V3 types, some of which were further divided into subtypes (Fig. 2; for review, see Goulding, 2009; Gosgnach, 2011; Kiehn, 2011; Kiehn and Dougherty, 2013).

The V0 neurons settle in the ventromedial spinal cord. They can be identified by the expression of the transcription factor Dbx1 (Pierani et al., 2001; Lanuza et al., 2004; Talpalar et al., 2013). The subdivision of V0 neurons into subtypes is based on transmitter phenotype, and these subtypes include dorsally located inhibitory $\mathrm{V}_{\mathrm{D}}$ neurons $\left(\operatorname{Pax} 7, E v \times 1^{-}\right)$, ventrally located glutamatergic $\mathrm{VO}_{v}$ neurons (Evx1), and cholinergic $\mathrm{V}_{\mathrm{C}}$ neurons (Pitx2) located near the central canal. Both $\mathrm{VO}_{\mathrm{D}}$ and $\mathrm{V} \mathrm{O}_{\mathrm{V}}$ subtypes project their axons contralaterally (Pierani et al., 2001) and represent major types of CINs involved in left-right alternation of neuronal activity in the spinal cord (Lanuza et al., 2004; Talpalar et al., 2013). Moreover, the selective genetic ablation of these neurons has shown that these types of CINs are involved in left-right alternation in a speeddependent manner (Talpalar et al., 2013). The $\mathrm{V}_{\mathrm{D}}$ neurons are essential for left-right alternation at slow locomotor speeds, and their ablation has little effect on locomotion at higher speeds. In contrast, the $\mathrm{V}_{\mathrm{V}}$ ablated mice show normal left-right alternation at slow speeds but switch to left-right synchronous activity at higher locomotor speeds (Talpalar et al., 2013).

The V1 neurons, expressing En1, are a heterogeneous group of inhibitory, ipsilaterally projecting interneurons (Fig. 2). Different subtypes of these neurons are involved in different inhibitory functions in the spinal cord, such as reciprocal (la interneurons) and recurrent (Renshaw cells) inhibition. A subpopulation of these neurons was found necessary for generating fast locomotor activity and, hence, can play a role in regulating the locomotor speed (Gosgnach et al., 2006; Zhang et al., 2014). These neurons, along with V2b neurons (see below), are involved in securing flexor-extensor alternation in the spinal cord. Abrogating neurotransmission in both V1 and V2b neuron types in the isolated spinal cord resulted in a synchronous flexor and extensor locomotor activity (Goulding et al., 2014; Zhang et al., 2014).

The V2 neurons express Lhx3 and are all ipsilaterally projecting. Two major subtypes of V2 neurons include (Fig. 2): excitatory V2a, expressing Chx10; and inhibitory V2b, expressing Gata2 or Gata3 (Al-Mosawie et al., 2007; Lundfald et al., 2007). During drug-induced fictive locomotion in isolated spinal cord, about half of the V2a interneurons receive rhythmic synaptic drive, which increases with locomotor frequency, recruiting additional 


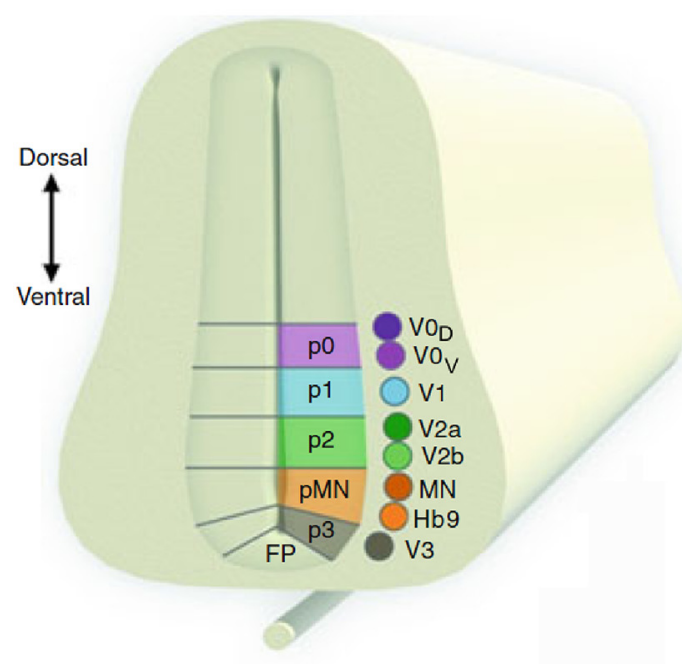

\begin{tabular}{|c|c|c|}
\hline Type & $\begin{array}{l}\text { Transcription } \\
\text { factors }\end{array}$ & Projections and transmitters \\
\hline $\mathrm{V} 0_{\mathrm{D}}$ & Dbx1/Evx1- & $\begin{array}{l}\text { Commissural neuron } \\
\text { Inhibitory - GABA/glycine }\end{array}$ \\
\hline$v 0_{v}$ & Dbx1/Evx1+ & $\begin{array}{l}\text { Commissural neuron } \\
\text { Excitatory - glutamate }\end{array}$ \\
\hline$V_{1}$ & En1 & $\begin{array}{l}\text { Ipsilateral projection } \\
\text { Inhibitory - GABA/glycine }\end{array}$ \\
\hline V2a & Chxi10 & $\begin{array}{l}\text { Ipsilateral projection } \\
\text { Excitatory - glutamate }\end{array}$ \\
\hline V2b & Gata2/3 & $\begin{array}{l}\text { Ipsilateral projection } \\
\text { Inhibitory - GABA/glycine }\end{array}$ \\
\hline $\mathrm{MN}$ & $\mathrm{Hb9}$ & Somatic motor neuron - Acetylcholine \\
\hline $\mathrm{Hb} 9$ & $\mathrm{Hb9}$ & $\begin{array}{l}\text { Ipsilateral projection } \\
\text { Excitatory - glutamate }\end{array}$ \\
\hline V3 & Sim1 & $\begin{array}{l}\text { Commissural neuron ( } 85 \%) \\
\text { Ipsilateral projection (15\%) } \\
\text { Excitatory - glutamate }\end{array}$ \\
\hline
\end{tabular}

Figure 2. Molecular code determines the identity of ventral spinal neurons. Morphogens secreted from the floor plate and roof plate set up concentration gradients in the ventricular zone to specify progenitor domains p0-p3 and pMN, characterized by their differential expression of transcription factors. When the progenitor cells mature, they migrate laterally and are called V0-V3, Hb9, and motor neurons. The table on the right depicts the main transcription factors in the five cardinal classes of ventrally located neurons (V0-V3, Hb9) and motor neurons, the projection pattern, and the transmitter phenotype of these neurons. Dbx1, developing brain homeobox 1; Evx1, even-skipped homeobox; En1, engrailed 1; Chx10, Ceh-10 homeodomain-containing homolog; Gata2/3, GATA binding proteins 2 and 3; Sim 1, single-minded homolog 1; Hb9, homeobox 9; FP, floor plate. Reproduced from Kiehn and Dougherty (2013), their Figure 38.8, with permission.

V2a neurons at higher locomotor frequencies (Zhong et al., 2011). Genetic ablation of V2a neurons results in changes similar to those produced by the ablation of $\mathrm{VO}_{\mathrm{V}}$ neurons, as follows: mutant mice maintain left-right alternating activity at low locomotor speeds and switch to left-right synchrony at high speeds (Crone et al., 2008, 2009). The similarity in the locomotor patterns seen following $\mathrm{V} 2 \mathrm{a}$ and $\mathrm{VO}_{\mathrm{V}}$ neuronal ablations suggests that a subpopulation of $\mathrm{V} 2 \mathrm{a}$ neurons provides excitatory drive to the $\mathrm{VO}_{\mathrm{V}}$ commissural pathway (Kiehn, 2011; Shevtsova et al., 2015). This is further supported by the demonstration of $\mathrm{V} 2 \mathrm{a}$ terminals on $\mathrm{V}_{\mathrm{V}}$ somata (Crone et al., 2008).

As mentioned above, the V2b neurons, along with V1 neurons, support flexor-extensor alternation in the intact cord, which can be disturbed only by silencing both of these neuron types (Zhang et al., 2014; Goulding et al., 2014). Flexor-extensor alternation is also maintained in a hemisected spinal cord, where this alternation is entirely supported by V2b neurons. Synaptic silencing of V2b neurons in hemicords results in flexor-extensor synchrony (Zhang et al., 2014). Therefore, in contrast to V1 neurons, the activity of $\mathrm{V} 2 \mathrm{~b}$ neurons depends on inputs from ipsilateral circuits.

The V3 neurons express Sim1 and are mainly excitatory commissural neurons (Zhang et al., 2008). Silencing of these neurons does not affect left-right or flexor-extensor alternation. It is suggested that V3 neurons participate in maintaining a stable, symmetrical rhythm; silencing of these neurons increases the variability of bursting amplitude and durations (Zhang et al., 2008).

\section{Spinal interneurons involved in locomotor rhythm generation: Shox2 cells}

The excitatory, ipsilaterally projecting V2a neurons could be considered potential candidates for the rhythmgenerating neurons in the mammalian spinal cord. However, ablation of these neurons does not affect the rhythm (Crone et al., 2008). Difficulties in the identification of specific rhythm-generating neurons may occur because these neurons come from dorsal progenitors that migrate ventrally or because they are spread sparsely across known ventral neuron classes. Shox2 expression was found in a subset of Chx10-expressing V2a neurons, and in non-V2a neurons coming from various dorsal and ventral progenitors (Fig. $3 A$ ). All of these neurons are excitatory and ipsilaterally projecting (Dougherty et al., 2013). Most Shox $2^{+}$neurons are rhythmically active during locomotion, and they show heterogeneity in target projections, projecting to other Shox ${ }^{+}$neurons, CINs, and/or motoneurons (Fig. $3 A$ ). Either short-term or long-term silencing of the Shox2 population resulted in a reduction in the locomotor frequency measured from ventral root recordings during both drug-evoked and brainstem stimulation-evoked locomotion, suggesting that they play a role in rhythm generation. Ablation of the Shox $2^{+}$ Chx $10^{+}$(V2a) subset resulted in an increase in the variability of burst amplitude and cycle period but had no effect on locomotor frequency. Therefore, only the Shox $2^{+} \mathrm{Ch} \times 10^{-}$(non-V2a) neurons were concluded to be part of the rhythm generator for locomotion (Fig. 3A). However, a rhythm remained, albeit slower, after Shox2 silencing, demonstrating that Shox $2^{+}$neurons are not the 
A

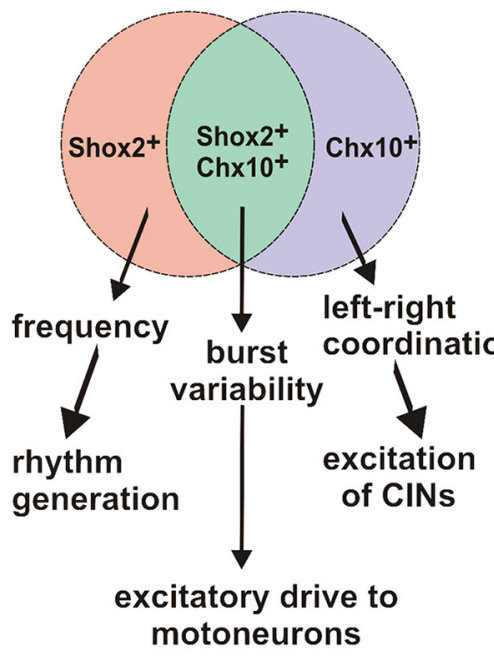

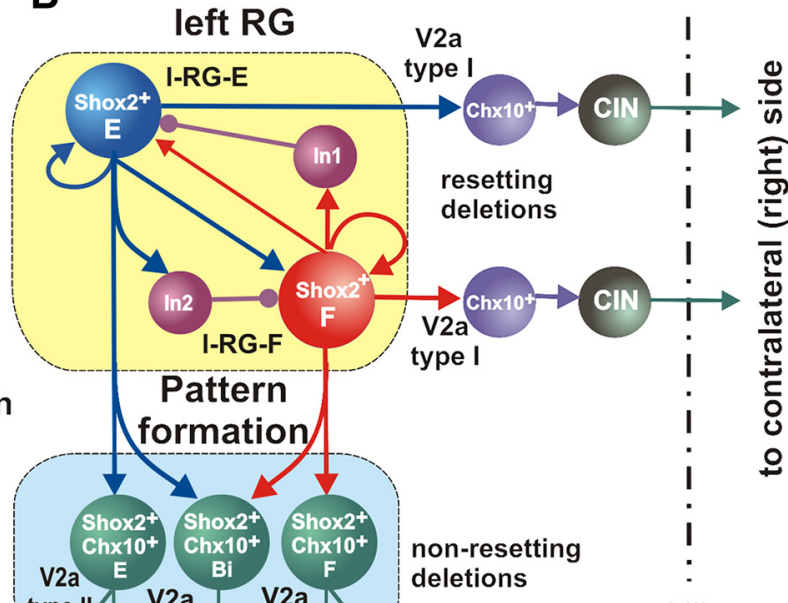

midline
B

type

type IV $\begin{gathered}\text { V2a } \\ \text { type II }\end{gathered}$ type II

to ipsilateral motoneurons

\section{C1}

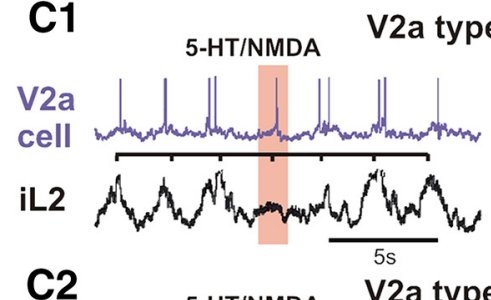

C2 5-HT/NMDA

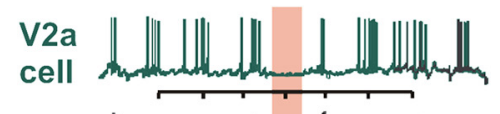

iL2

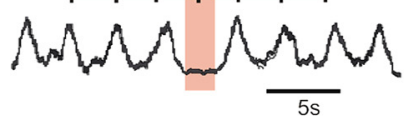

C3

CIN
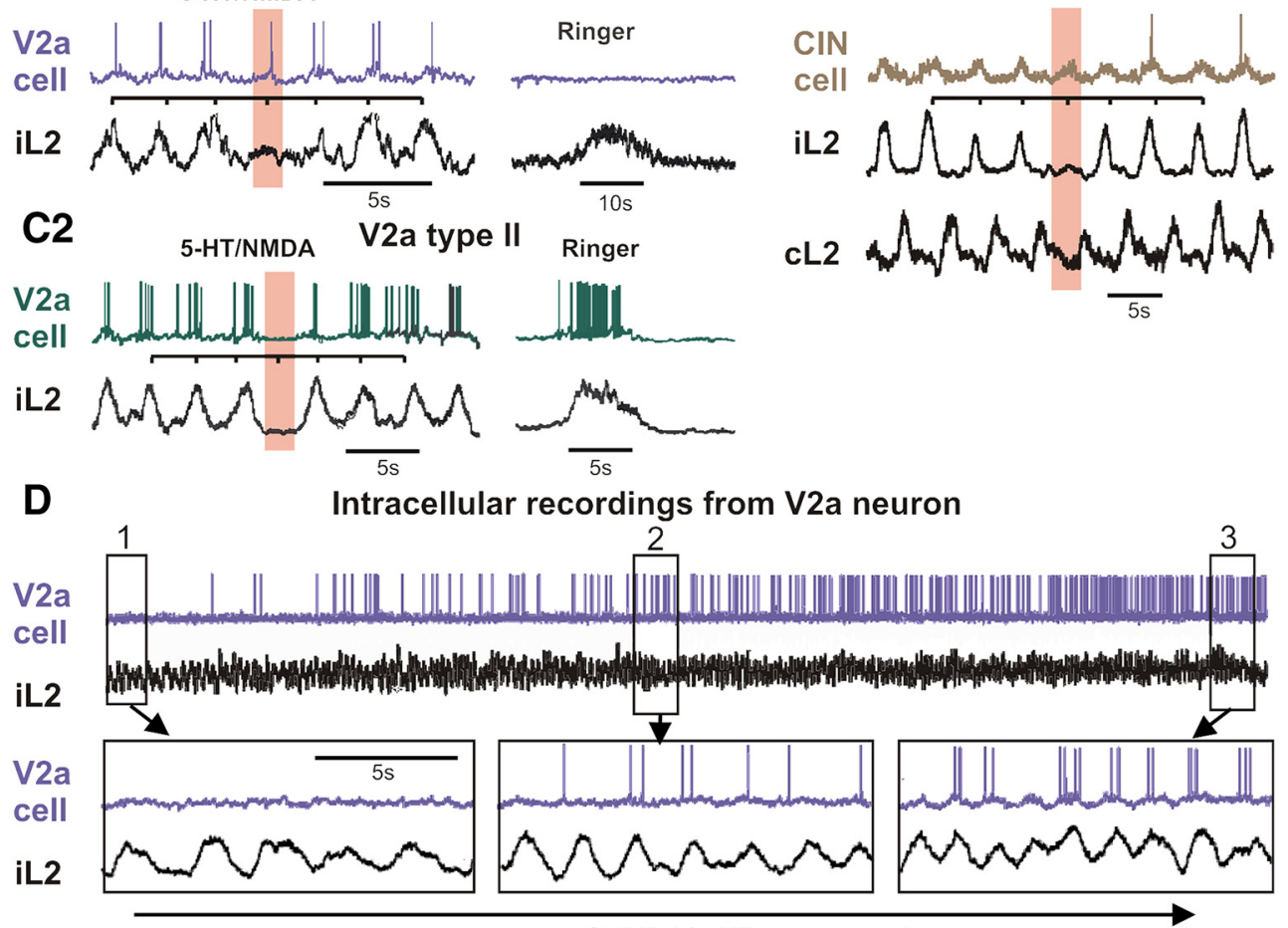

increase of NMDA/5-HT concentration

Figure 3. Shox $2^{+}$neurons and two types of V2a $\left(\mathrm{Ch} \times 10^{+}\right)$cells. $\boldsymbol{A}$, The suggested different functional roles of Shox2 $2^{+}$(non-V2a), Shox2 ${ }^{+} \mathrm{Ch} \times 10^{+}$ (V2a), and Shox2 ${ }^{\text {off }} \mathrm{Chx} 10^{+}$(V2a) neurons. Reproduced from Dougherty et al. (2013), their Figure 8A, with permission. B, Different roles of V2a type I $\left(C h \times 10^{+}\right.$Shox $\left.2^{\text {off }}\right)$ and V2a type II $\left(C h \times 10^{+}\right.$Shox $\left.2^{+}\right)$neurons. C1, V2a type I neuron continued to receive rhythmic excitatory synaptic inputs and fired rhythmic bursts during a non-resetting ipsilateral flexor deletion (iL2) occurring during NMDA/5-HT-induced fictive locomotion (currentclamp recording). Deletion is indicated by the pink bar. Recordings on the right show that this neuron did not receive any synaptic drive during a spontaneous nonlocomotor activity observed in the ipsilateral motor output (iL2). C2, V2a type II neuron was silent and lost synaptic drive during a non-resetting flexor (iL2) deletion. This neuron was excited and fired a prolonged burst of action potentials during a spontaneous nonlocomotor iL2 burst of activity (right). C3, Activity of a flexor-related CIN during a non-resetting flexor deletion. One can see rhythmic membrane potential oscillations in phase with the iL2 root activity, and the neuron continued to oscillate during flexor deletion. $\mathbf{C 1}, \mathbf{C 2}$, and $\mathbf{C 3}$ are reproduced from Zhong et al. (2012), their Figures 5D,E, 6C,D, and 4B, respectively, with permission. $\boldsymbol{D}$, Intracellular recording from V2a neuron exhibiting an increased firing activity with increased drug (NMDA/5-HT) concentration. Insets 1, 2, and 3 show expanded recordings indicated in the top diagram. The iL2 trace represents smoothed and filtered ventral root activity. Reproduced from Zhong et al. (2011), their Figure 4a-d, with permission. 
only rhythm-generating neurons. Other components of the rhythm generator are not known at this time. The only current candidate is the $\mathrm{Hb} 9$ interneuron population (Fig. 2), which is also suggested to be involved in rhythm generation (Wilson et al., 2005; Hinckley and ZiskindConhaim, 2006; Brocard et al., 2010, 2013). It was shown that their activity does not precede burst initiation in motor outputs, suggesting that they may contribute to maintenance of the locomotor rhythm but cannot represent the sole rhythm-generating kernel (Kwan et al., 2009). Whether they are another constituent population of the rhythm generator remains to be directly tested.

The intrinsic neuronal properties involved in generating rhythmic bursting in Shox2 cells are currently unknown. A series of previous models of the mammalian spinal rhythm generator suggested that this rhythmic activity is based on the persistent sodium current, $I_{\mathrm{NaP}}$ (Rybak et al., 2006a,b,2014; McCrea and Rybak, 2007; Sherwood et al., 2011; Zhong et al., 2012; Brocard et al., 2013). This suggestion was indirectly supported by a series of experimental studies performed in different laboratories (Zhong et al., 2007; Tazerart et al., 2007, 2008; Ziskind-Conhaim et al., 2008; Brocard et al., 2010, 2013). Moreover, the presence and involvement of $I_{\mathrm{NaP}}$ for rhythm generation in spinal $\mathrm{Hb9}$ neurons has been explicitly demonstrated (Brocard et al., 2013).

\section{Ipsilaterally projecting, excitatory V2a interneurons}

Based on Shox2 expression, the population of V2a (Chx10) neurons can be divided into the following two groups: Shox2 $2^{+}$and Shox2 $2^{-}$(Fig. 3A; Dougherty et al., 2013). When Shox2-expressing V2a neurons were ablated, there was no effect on left-right coordination. The only observable phenotype was an increase in the variability of burst amplitude and cycle period, which was also seen in the complete Shox2 mutants and the V2a mutants. This, together with the study by Crone et al. $(2008,2009)$, indicates that the V2a neurons that do not express Shox $2\left(\mathrm{Ch} \times 10^{+}\right.$and Shox $\left.2^{-}\right)$are the neurons responsible for left-right deficits seen in the V2a ablated mice, and the Shox $2^{+}$V2a neurons provide input to motoneurons (Fig. $3 A, B$ ).

The functional separation of $\mathrm{Shox}^{+} \mathrm{Ch} \times 10^{+}$and Shox $2^{-}$Chx $10^{+}$neurons fits very well with the results of a previous study, Zhong et al. (2012), which also identified two different subtypes of V2a interneurons. In that study, the neurons were classified based on analysis of their activity during non-resetting deletions. According to that classification, the V2a type I neurons maintained rhythmic activity at the times when bursts in the motor output (ipsilateral ventral root) were missed (Fig. 3C1), whereas the V2a type II neurons had missing activation consistent with the burst deletions seen in the motor output (Fig. 3C2). In addition, during nonlocomoting conditions (NMDA and 5-HT washed out), the V2a type I neurons did not show activation together with ventral root "nonlocomotor" bursts (Fig. 3C1), whereas the V2a type II neurons did exhibit activation consistent with such nonlocomotor activity in the motor output (Fig. 3C2). Interestingly, the commissural neurons identified in this study also maintained bursts during non-resetting deletions in the motor output (Fig. 3C3), similar to V2a type I. All of these data are consistent with the different roles of V2a type I (Chx10 Shox $\left.2^{-}\right)$neurons and V2a type II $\left(\mathrm{Ch} \times 10^{+}\right.$Shox $\left.2^{+}\right)$neurons in the spinal circuitry suggested above. The former neurons project to CINs and contribute to left-right alternation, whereas the latter neurons may belong to $P F$ and mediate RG input to ipsilateral motoneurons (Fig. $3 A, B$ ).

There are some other important properties of V2a neurons. Some of these neurons show a strong increase in activity and recruitment as NMDA/5-HT concentrations, and therefore locomotor frequency, are increased (Zhong et al., 2011; Fig. 3D). Additionally, genetic ablation of these neurons disturbed left-right alternation at high locomotor frequencies (Crone et al., 2008, 2009), suggesting that these neurons play a critical role in the support of left-right alternation in the spinal cord at high locomotor frequencies.

\section{Flexor-extensor asymmetry in the organization of locomotor activity}

Most bipartite models, from the first model of Graham Brown (1914) to the two-level model of McCrea and Rybak (2008), assumed a symmetrical organization of the rhythm generators in regard to flexor and extensor halfcenters and their interactions. Nevertheless, asymmetric, flexor-dominated architectures of rhythm generation have been also proposed (Pearson and Duysens, 1976; Duysens, 1977; Zhong et al., 2012; Duysens et al., 2013; Machado et al., 2015). Two recent findings from studies in the isolated rodent spinal cord with drug-induced fictive locomotion have recently provided indirect support of the asymmetric flexor-dominated organization. First, the analysis of nonresetting deletions in these preparations revealed only the following two types of deletions: missing bursts in the flexor-dominated ventral root (L2) were accompanied by sustained activity in the ipsilateral extensor-dominated root (L5); whereas missing extensor bursts usually occurred without obvious disturbances of the ipsilateral flexor rhythmic activity (Zhong et al., 2012; Fig. 4A). Second, the analysis of changes in the duration of flexor and extensor phases with an increase in oscillation frequency during NMDA/5-HT-evoked fictive locomotion in the isolated mouse spinal cord has shown that the duration of flexor phase changes much less than the duration of the extensor phase (Talpalar et al., 2013; Shevtsova et al., 2015; Fig. 4B), which also fits with similar phase measurements performed in cats in vivo (Halbertsma, 1983; Frigon and Gossard, 2009). Therefore, one can suggest that extensor-related neurons in the spinal rhythm generator do not generate intrinsic rhythmic activity themselves but exhibit rhythmic bursting due to inhibition from the corresponding flexor-related rhythm-generating neurons. In this case, extensor phases may represent intervals of tonic activity between inhibitory states corresponding to flexor bursts. The potential dominance and evolutionary primacy of flexor activity have been confirmed recently by Machado et al. (2015). 
A1

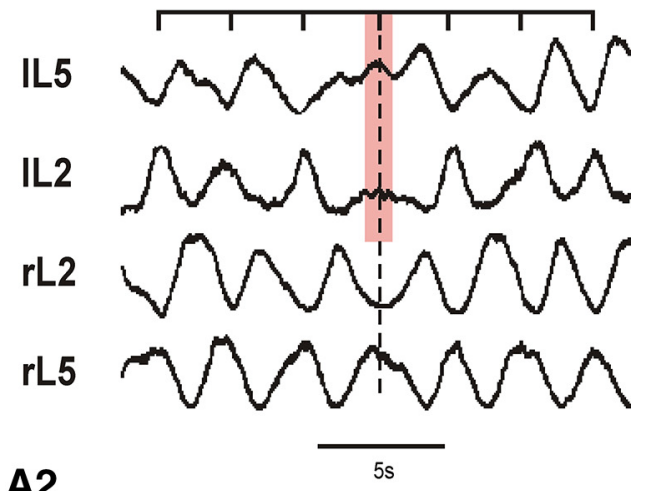

A2

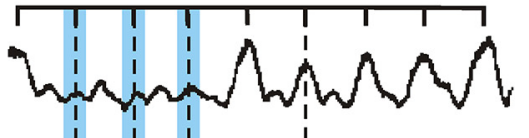

IL5

IL2

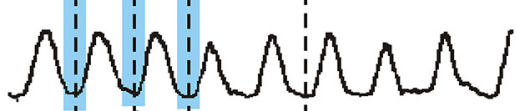

rL2

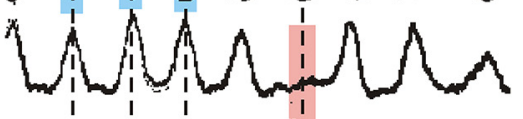

rL5

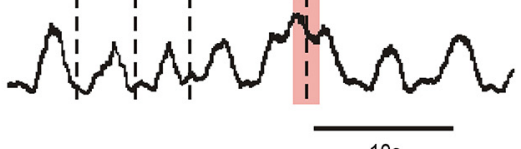

$10 \mathrm{~s}$

- flexor deletions

- extensor

B

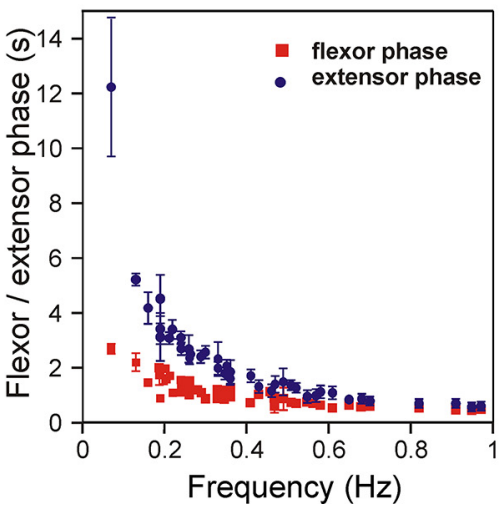

Figure 4. Flexor-extensor asymmetry. A1, A2, Flexor and extensor deletions during NMDA/5-HT-induced fictive locomotion in the isolated rat spinal cord. Smoothed and rectified traces of motoneuron activity recorded from the left (IL2, IL5) and right (rL2, rL5) lumbar ventral roots. L2 recordings show predominantly flexor motoneuron activity, while L5 recordings show predominantly extensor activity. The bars above each set of traces show the expected timing of the bursts if the rhythm were unperturbed during the deletion. $\boldsymbol{A} \boldsymbol{1}$ shows an example of a non-resetting flexor deletion recorded from the IL2 root (indicated by the pink bar) accompanied by tonic activity in the ipsilateral extensor (IL5) root, but with no obvious effects on flexor or extensor activity on the opposite side of the cord. A2 shows non-resetting extensor deletions (marked by blue bars) and a flexor deletion (marked by pink bar). During extensor deletions in IL5, the ipsilateral flexor activity (IL2) and contralateral activities were not perturbed, while the flexor deletion in rL2 was accompanied by tonic activity in the rL5 ventral root. Reproduced from Zhong et al. (2012), their Figure $1 \mathrm{Aa}, \mathrm{Ba}$, with

\section{Figure 4. continued}

permission. $\boldsymbol{B}$, Changes in flexor and extensor phase durations during NMDA/5-HT-induced fictive locomotion in the isolated mouse spinal cord as a function of locomotor frequency. Red filled squares and blue filled circles show average flexor and extensor phase durations, respectively. Reproduced from Shevtsova et al. (2015), their Figure 9C, with permission.

The above suggestion, however, looks contradictory to multiple data showing that extensor rhythmic activity can, under certain conditions, be generated without flexor activity. Specifically, using an optogenetic approach, Hägglund et al. (2013) have demonstrated that a locomotorlike rhythmic bursting can be induced unilaterally and independently in flexor and extensor networks. A resolution of this contradiction could be achieved based on a suggestion that both flexor-related and extensor-related centers are intrinsically rhythmogenic, but the expression of their intrinsic rhythmicity may depend on various factors, such as general neuronal excitability or external drive to neurons in these populations (Shevtsova et al., 2015; or Molkov et al., 2015). The other important suggestion here is that, during locomotor activity, intrinsic rhythmicity is always present in flexor RG circuits, but the rhythmicity of extensor RG circuits is conditional and may depend on, for example, the type of experimental preparations (various in vivo preparations, isolated spinal cord in vitro) or the methods used to evoke the rhythm (neuroactive drug application, electrical stimulation of brainstem, afferent/ dorsal root stimulation; Shevtsova et al., 2015).

This idea was explicitly implemented in the models of Shevtsova et al. (2015) and Molkov et al (2015), in which both flexor and extensor rhythm-generating populations (representing the corresponding locomotor centers or half-centers) could generate rhythmic bursting depending on conditions, but normally only flexor populations (centers) on each side operated in the intrinsic bursting regime while the extensor populations operated in a state of tonic activity and exhibited bursting due to the rhythmic inhibition from the ipsilateral flexor centers.

Each RG population in the model of Shevtsova et al. (2015), representing either flexor or extensor centers, consisted of 200 neurons modeled on the Hodgkin-Huxley style. The intrinsic rhythmic bursting in each population was based on a persistent (slowly inactivating) sodium current, $I_{\mathrm{NaP}}$, incorporated into each neuron, and sparse mutual excitatory synaptic interactions within the population. Figure $5 A-D$ shows the results of modeling a single isolated $R G$ population during a slow ramp increase of neuronal excitation, defined by the average neuronal leakage reversal potential $\bar{E}_{L}$. At low values of $\bar{E}_{L}$, the population was silent (Fig. $5 A, B)$. Bursting emerged as $\bar{E}_{\mathrm{L}}$ depolarized (Fig. 5A,B; see also Fig. 5G, blue area). With a further increase of $E_{\mathrm{L}}$, the burst frequency monotonically increased (Fig. 5B,C). The burst amplitude initially went up (Fig. $5 B, D$ ), because of the increasing synchronization of bursts generated by individual neurons. Then, with further depolarization, the amplitude progressively decreased (Fig. $5 B, D$ ) due to $I_{\mathrm{NaP}}$ inactivation in each neuron, leading 
A
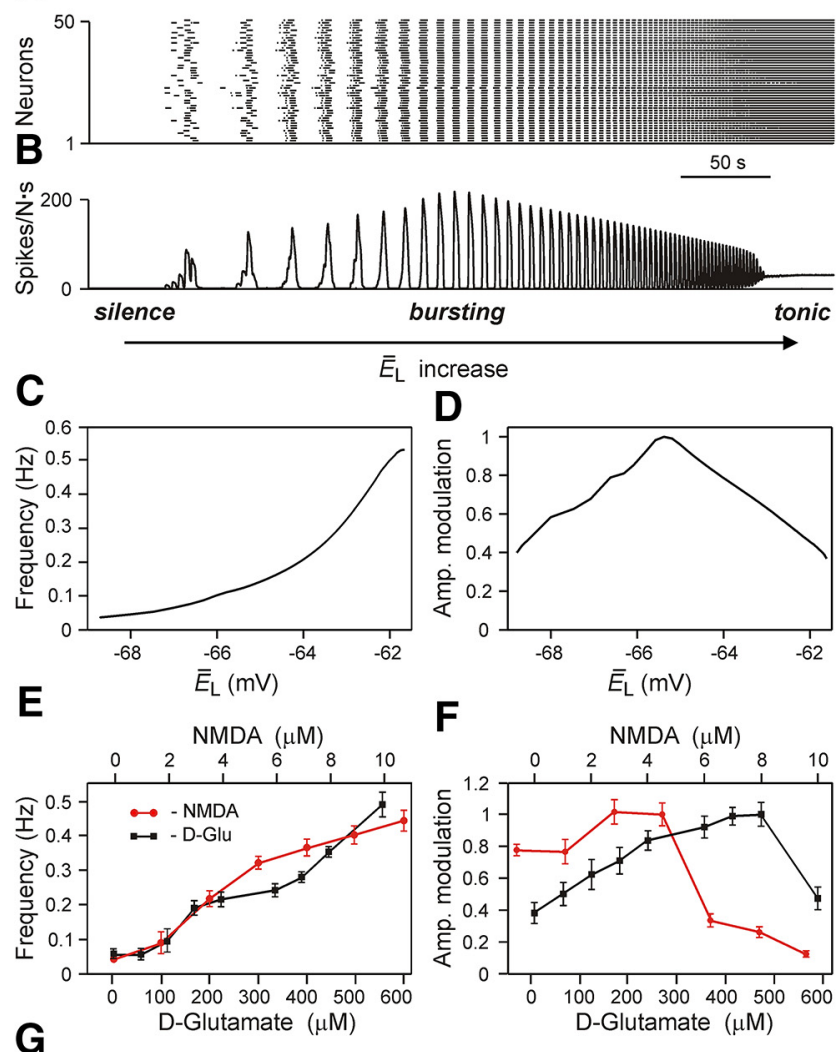

$\mathbf{F}$
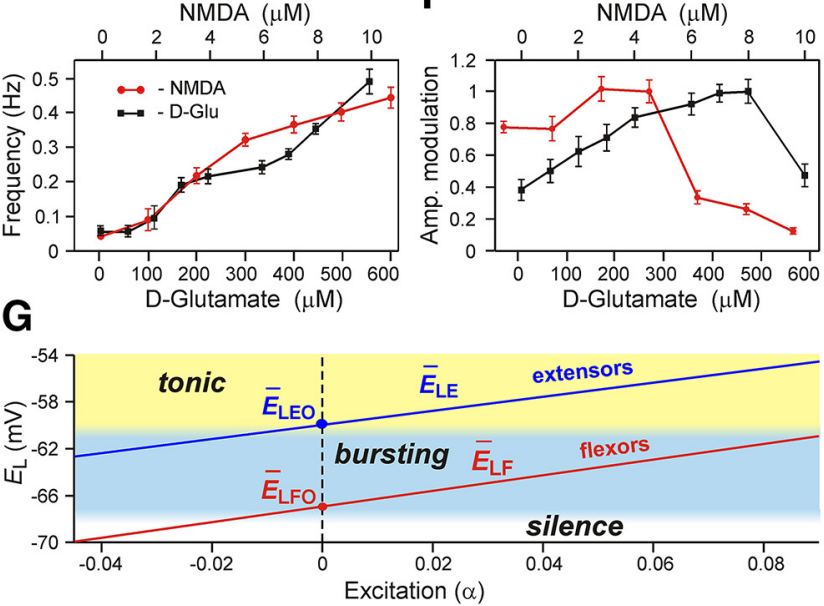

Figure 5. Modeling of an isolated rhythm-generating population. A, Raster plot of the activity of 50 neurons from the 200-neuron population. Each horizontal line represents a neuron, and each dot represents a spike. $\boldsymbol{B}$, Integrated population activity represented by the average histogram of population activity [spikes/(neuron $\times \mathrm{s}$ ), bin $=100 \mathrm{~ms}$ ]. In $\boldsymbol{A}$ and $\boldsymbol{B}$, the average leakage reversal potential $\left(\bar{E}_{L}\right)$ defining the average level of neuronal excitation was linearly increased from -70 to $-58 \mathrm{mV}$ for $400 \mathrm{~s}$. Voltage regions of silence, bursting, and tonic activity are denoted at the bottom. Bursting emerges at lower values of $\bar{E}_{\mathrm{L}}$ in a limited number of neurons. With increasing $\bar{E}_{\mathrm{L}}$, more neurons become involved and the population bursting becomes strongly synchronized. A further increase of $\bar{E}_{\mathrm{L}}$ leads to a transition to tonic activity. $\boldsymbol{C}$ and $\boldsymbol{D}$, respectively, show the frequency of and amplitude of population activity as functions of $\bar{E}_{\mathrm{L}}$. $\boldsymbol{E}$ and $\boldsymbol{F}$, respectively, show the frequency and amplitude of NMDA/5-HT-evoked locomotor activity in the isolated mouse spinal cord recorded in vitro from the flexor ventral root as a function of NMDA (red circles) or D-glutamate (black squares) concentration (the amplitude was normalized with respect to the maximal amplitude). Graphs display the mean \pm SD ( $n=20$ each). $\mathbf{G}$ shows changes of $\bar{E}_{\mathrm{L}}$ for flexor $\left(\bar{E}_{\mathrm{LF}}\right.$, red line) and extensor $\left(\bar{E}_{\mathrm{LE}}\right.$, blue line) $R G$ centers during increasing neuronal excitation with an increase in drug concentration [defined by parameter $\alpha,\left(\bar{E}_{L \mathrm{Li}}=\bar{E}_{\mathrm{LO}} \cdot(1-\alpha)\right)$ ] across areas for silence (white), bursting (blue), and tonic (yellow) population activity. This figure is reproduced from Shevtsova et al. (2015), their Figure 2, with permission. to a reduction of spike frequency in neuronal bursts (Butera et al., 1999; Rybak et al., 2004). Finally, for the larger (most depolarized) values of $\bar{E}_{L}$, bursting switched into sustained or tonic activity (Fig. $5 A, B$; see also Fig. 5G, yellow area). A similar transition from a silent state to bursting and tonic spiking with a progressive increase of $\bar{E}_{\mathrm{L}}$ was shown in models of other neural oscillators (Cymbalyuk et al., 2002). The simulated effects of the increase of neuronal excitation on the population burst frequency and amplitude (Fig. $5 C, D$ ) are qualitatively similar to the reported effects of increased concentrations of neuroactive drugs, such as NMDA, on the frequency and amplitude of locomotor oscillations in the isolated spinal cord (Talpalar and Kiehn, 2010). In these experiments, the bursting frequency recorded from the flexor ventral root (L2) increased with increased drug concentration, while the amplitude initially increased and then decreased (Fig. 5E,F). This correspondence between the experimental and modeling data allowed the suggestion that the experimentally observed increase of locomotor frequency with increasing NMDA concentration resulted from a drug-induced increase in the average neuronal excitability defined in the model by $\bar{E}_{\mathrm{L}}$. Therefore, changes in were used in the model as a tool for changing locomotor frequency to fit different speeds of drug-evoked locomotion (Shevtsova et al. 2015).

As shown in Figure $5, A$ and $B$, a population of neurons with $I_{\mathrm{NaP}}$-dependent bursting properties and mutually excitatory synaptic interconnections can be silent, generate intrinsic bursting, or exhibit sustained (tonic) activity, depending on the average level of neuronal excitation (see also Butera et al., 1999; Smith et al., 2000; Rybak et al., 2003, 2004, 2014; Jasinski et al., 2013). In the model of Shevtsova et al. (2015), the rhythm-generating population was used for the simulation of both flexor and extensor centers. Therefore, under certain conditions, for example at a particular range of neuronal excitation, each flexor and extensor RG center can generate rhythmic bursting. However, it was assumed that, under the experimental conditions considered, only flexor centers operate in a bursting mode, whereas the extensor centers, if isolated, are tonically active. This was reproduced in the model of Shevtsova et al. (2015) by extensor RG centers with a higher level of excitation (Fig. 5G, yellow area) compared with the flexor RG centers (Fig. 5G, blue area). To provide alternating flexor-extensor activity, the flexor and extensor RG centers were connected reciprocally via inhibitory neural populations (Fig. $6 A, B$ ). Therefore, each extensor RG center also exhibited rhythmic bursting, but this was entirely due to the rhythmic inhibition by the corresponding ipsilateral flexor center. Such asymmetric operation of flexor and extensor RG centers allowed the model to reproduce the specific patterns of motor activity in the spinal cord observed during spontaneous, non-resetting burst deletions, showing that missing flexor bursts were always accompanied by a sustained ipsilateral extensor activity, whereas missing extensor bursts occurred without an effect on flexor bursting (Fig. 4A1, A2, see also Zhong et al., 2012). 
A

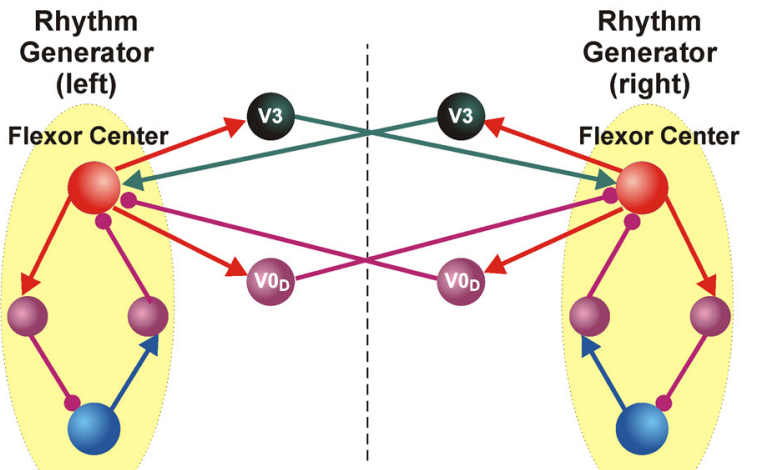

Extensor Center

Extensor Center

B

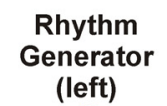

Flexor Center

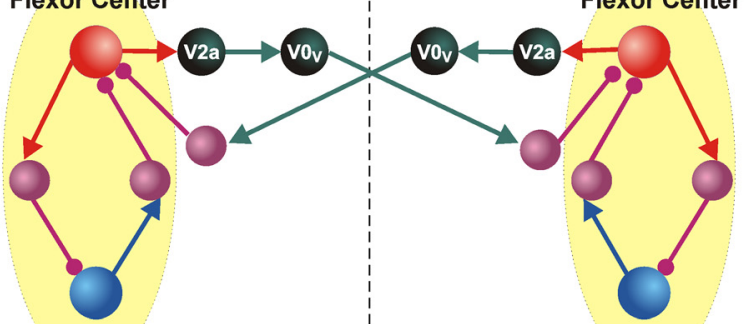

Extensor Center

Extensor Center
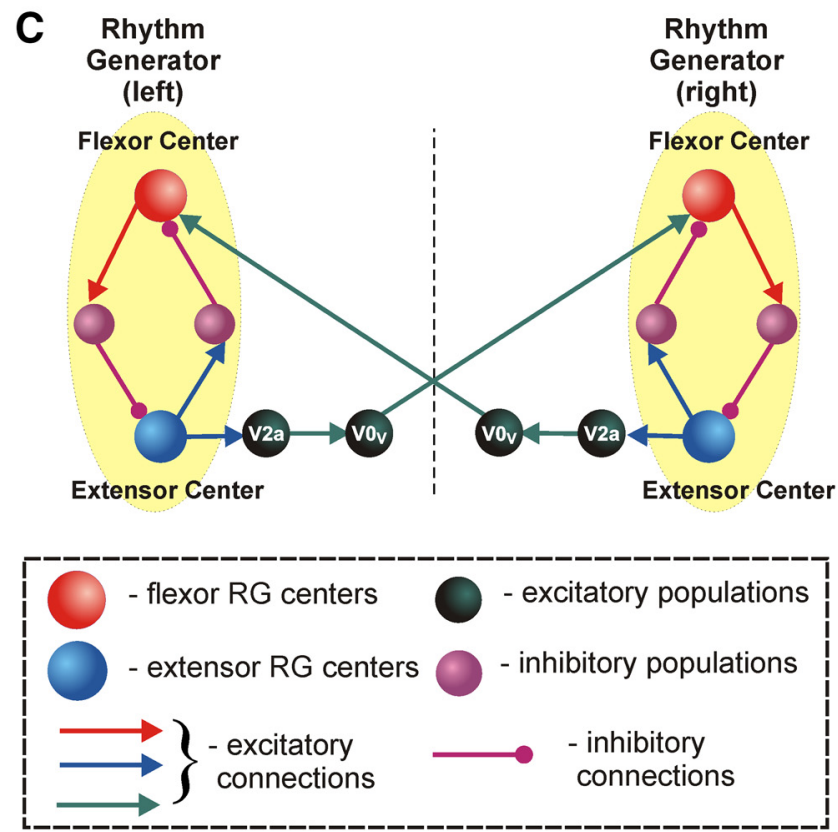

Figure 6. The proposed organization of the excitatory and inhibitory commissural pathways involved in left-right coordination of activity in the spinal cord. The RG centers and other neural populations are shown by spheres. Excitatory and inhibitory synaptic connections are represented by arrows and circles, respectively. $\boldsymbol{A}$, Organization of the excitatory (mediated by the V3 CINs) and inhibitory (mediated by the $\mathrm{V}_{\mathrm{D}} \mathrm{CINs}$ ) pathways. $\boldsymbol{B}$, $\boldsymbol{C}$, Two possible organizations of commissural pathways mediated by $\mathrm{V} 2 \mathrm{a}$ interneurons and $\mathrm{VO}_{\mathrm{V}} \mathrm{CINs}$.

\section{Left-right coordination of activity in the spinal cord: frequency-dependent role of $\mathrm{VO}_{\mathrm{D}}$ and $\mathrm{VO}_{\mathrm{v}} \mathrm{CINS}$}

The following types of CINs have been genetically identified in the spinal cord so far: the inhibitory $V O_{D}$, the excitatory $\mathrm{VO}_{\mathrm{V}}$, and the excitatory $\mathrm{V} 3 \mathrm{CINs}$ (Fig. 2). There are also dl6 neurons (Dyck et al., 2012), which are not considered here. The simplest connectivity schematic for the excitatory CIN pathways supporting left-right synchrony could be that in which these CINs (e.g., V3) would receive excitation from ipsilateral flexor centers and excite the contralateral flexor centers (Fig. $6 A$ ). In contrast, the VO CINs, both the inhibitory $\mathrm{VO}_{\mathrm{D}}$ and the excitatory $\mathrm{VO}_{\mathrm{V}}$ types, support left-right alternation (Talpalar et al., 2013). The inhibitory $\mathrm{V} \mathrm{O}_{\mathrm{D}} \mathrm{CIN}$ pathway could receive excitation from ipsilateral flexor centers and inhibit the contralateral flexor center (Fig. 6A).

The organization of the commissural pathways involving the excitatory $\mathrm{V}_{\mathrm{V}} \mathrm{CINs}$ promoting left-right alternation is expected to be more complicated. As described above (see Spinal interneurons identified from developmental and genetic studies; Crone et al., 2008; Kiehn, 2011), inputs to $V 0_{V}$ CINs can be mediated by the ipsilaterally projected $\mathrm{V} 2 \mathrm{a}$ neurons. Two possible organizations of $\mathrm{V}_{2} \mathrm{a}-\mathrm{V} \mathrm{O}_{\mathrm{v}}$ pathways promoting left-right alternation can be considered. One potential configuration suggests that the V2a neurons from these pathways receive excitatory inputs from the ipsilateral flexor centers and excite $\mathrm{VO}_{V}$ $\mathrm{CINs}$, whereas the $\mathrm{VO}_{\mathrm{V}} \mathrm{CINs}$ inhibit the contralateral flexor centers via some inhibitory interneurons (Kiehn, 2011, Talpalar et al., 2013; Shevtsova et al., 2015; Fig. 6B). The

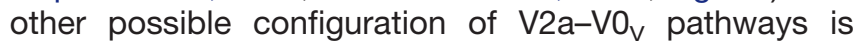
based on excitatory inputs to the V2a neurons from the ipsilateral extensor centers and direct excitatory input from the corresponding $\mathrm{V}_{\mathrm{V}} \mathrm{CINs}$ to the contralateral flexor centers (Shevtsova et al., 2015; Fig. 6C).

The frequency-dependent role of $\mathrm{V} \mathrm{O}_{\mathrm{D}}$ and $\mathrm{V} \mathrm{O}_{\mathrm{V}}$ neurons in left-right alternation of neural activity in the spinal cord was studied by Talpalar et al. (2013). They have shown that the ablation of both these types of CINs leads to left-right synchronized, hopping-like activity at all locomotor frequencies. Selective ablation of the inhibitory $\mathrm{V}_{\mathrm{D}}$ CINs disturbs left-right alternation at low frequencies, yet maintains alternation at high frequencies. In contrast, ablation of the excitatory $\mathrm{VO}_{\mathrm{V}} \mathrm{CINs}$ maintains alternation at low frequencies and switches to synchronized activity at high frequencies.

To reproduce and explain these findings using computational modeling, Shevtsova et al. (2015) developed two slightly different models, Model 1 and Model 2 (Fig. 7A,B). Each model contained left (I) and right ( $r$ ) RGs consisting of flexor (RG-F) and extensor (RG-E) rhythm-generating centers reciprocally inhibiting each other via Inrg-E and Inrg-F, respectively. In both models, the inhibitory left (I-CINi-F) and right (r-CINi-F) CIN populations, simulating the $\mathrm{V}_{\mathrm{D}} \mathrm{CINs}$, mediate mutual inhibition between left and right flexor centers (Fig. 6A). Also, the excitatory left CIN flexor (I-CINe-F) and right CIN flexor (r-CINe-F) populations, simulating excitatory CINs, which are conditionally associated with the V3 neurons, mediate mutual excita- 
A

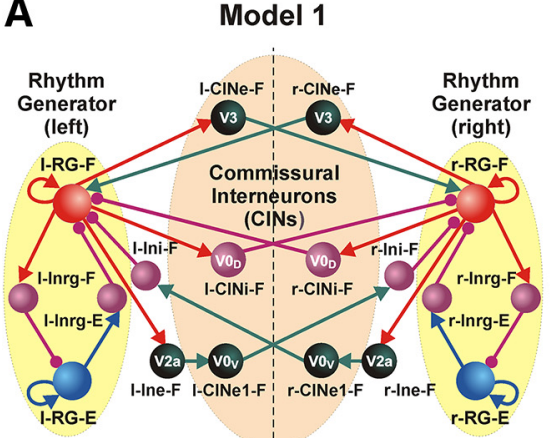

B

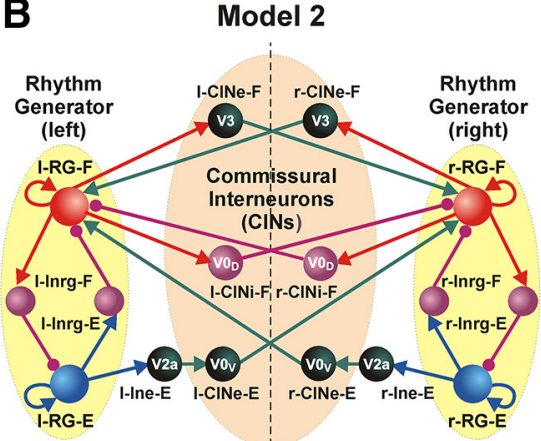

- extensor RG centers $\bigcirc$ - inhibitory populations

C1

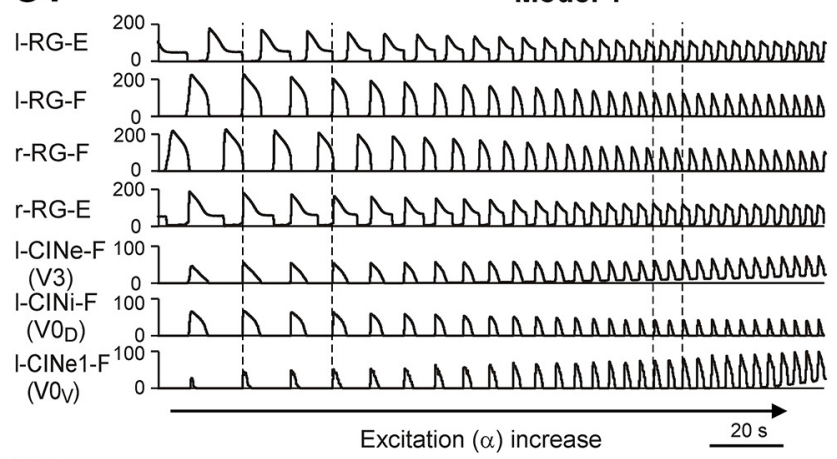

D1

I-RG-E

I-RG

r-RG-F

$r-R G-$

I-C

I-CIN

I-CINi-F

(VOD)

I-CINe-
Model 2

${ }^{200}$ ${ }^{200}$

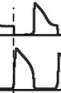
$\left.\begin{array}{c}200 \\ 0\end{array}\right] \Omega$ 200 200 $0 \mathrm{~h}$

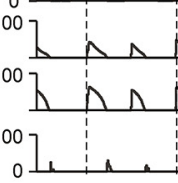

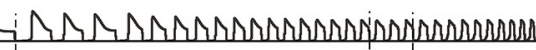

C2

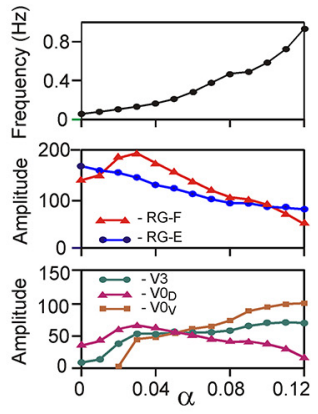

D2

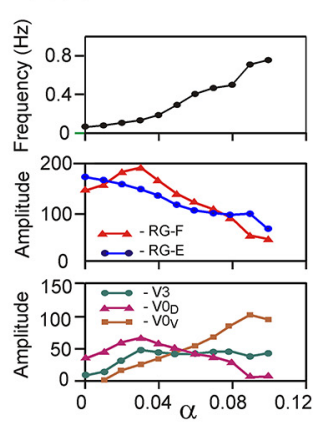

Figure 7. Modeling the coordination of left and right rhythm generators in the spinal cord via several parallel CIN pathways. $\boldsymbol{A}$ and $\boldsymbol{B}$ show schematics of Model 1 and Model 2, respectively. Neural populations are shown by spheres. Each RG population (representing the flexor or extensor centers) contained 200 neurons; all other populations consisted of 50 neurons each. All neurons were modeled in the Hodgkin-Huxley style. Excitatory and inhibitory synaptic connections are represented by arrows and circles, respectively. Prefix l- or $r$ - in population name indicates left or right. The RG on each side of the cord includes flexor and extensor RG centers (RG-F and RG-E, respectively) interacting via the inhibitory Inrg-F and Inrg-E populations. Suffix F- or E- in population name indicates that the population is coactive with the flexor or extensor RG center,

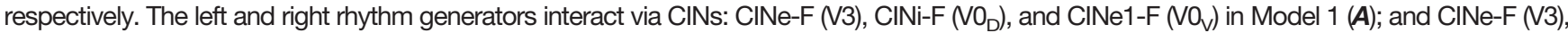
CINi-F (VOD), and CINe-E (VOV) in Model 2 (B). The full mathematical description of the model can be found in the study by Shevtsova et al. 2015. Reproduced from Shevtsova et al. (2015), their Figure 1, with permission. $\boldsymbol{C} 1$ and $\boldsymbol{D} 1$ show the performances of Model 1 and Model 2, respectively, in response to a slow ramp increase of neuronal excitation. The activity of all four RG centers (left and right RG-F and RG-E populations) and left $\mathrm{CIN}$ populations are shown as average histograms of population activity [spikes/(neuron $\times \mathrm{s}$ ), bin $=100 \mathrm{~ms}$ ] in response to a slow ramp increase of neuronal excitation $\alpha$ ( $\alpha$ increased for $100 \mathrm{~s}$ ). Note the maintenance of left-right and flexor-extensor alternation and acceleration of rhythmic activity in both models. The vertical dashed lines indicate the beginning of the left flexor phases at lower (the left lines) and higher (the right lines) values of $\alpha$. Reproduced from Shevtsova et al. (2015), their Figure 4, with permission. C2 and D2 show changes of the key model characteristics in Model 1 and Model 2, respectively, in response to a slow ramp increase of neuronal excitation. In both panels, the top diagram shows changes in the frequency of oscillation; the middle diagram represents changes in the amplitude of the activity of I-RG-F (red) and I-RG-E (blue) centers; and the bottom diagram shows changes in the amplitude of activity of $\mathrm{V} 3$ (green), $\mathrm{V} \mathrm{O}_{\mathrm{D}}$ (purple), and V0 $\mathrm{V}$ (brown) CIN populations. Reproduced from Shevtsova et al. (2015), their Figure 5, with permission. 
tion between these centers (Fig. 6A). In addition, both models have commissural pathways that include the sequentially connected $\mathrm{V} 2 \mathrm{a}$ and $\mathrm{V}_{\mathrm{v}}$ populations. The only difference between the models is in the organization of the $\mathrm{V} 2 \mathrm{a}-\mathrm{V} 0_{\mathrm{V}}$ pathways. In Model 1 , these pathways are organized as in Figure $6 B$, so that the left V2a flexor and right V2a flexor populations receive excitatory inputs from the ipsilateral flexor centers (I-RG-F and $r-R G-F)$, and excite the corresponding $\mathrm{VO}_{\mathrm{V}}$ extensor populations (I$\mathrm{CINe1-F}$ and $\mathrm{r}-\mathrm{ClNe} 1-\mathrm{F}$ ) which project to the contralateral populations of inhibitory interneurons that inhibit the contralateral flexor centers (Fig. 7A). In Model 2, these pathways are organized as in Figure $6 C$, so that the left and right V2a populations receive excitatory inputs from the ipsilateral extensor centers (I-RG-E and r-RG-E), and the corresponding $\mathrm{VO}_{v}$ populations (I-CINe-E and $\left.r-\mathrm{CINe}-\mathrm{E}\right)$ directly project to and excite the contralateral flexor centers (Fig. 7B). Separate consideration of these two models allowed independent investigation of each of the two $\mathrm{V} 2 \mathrm{a}-\mathrm{V} \mathrm{O}_{\mathrm{v}}$ pathways suggested. However, the authors have not excluded the possibility that both pathways are present in the real spinal cord network, which would result in a simple merging of both models into a single united model (Shevtsova et al., 2015).

To evaluate the performance of both models at different locomotor speeds, and the speed-dependent contribution of different CIN pathways and neuron types to the maintenance of left-right coordination, the locomotor frequency was progressively increased by increasing the parameter $\alpha$ that characterized an increase of average neuronal excitation $\left(E_{L}\right)$ in all neuron populations of the model (Fig. 5G and legend). Hence, the increase in $\alpha$ values simulated the increase in NMDA concentration that was used in the experiments in the study by Talpalar et al. (2013) to increase the frequency of locomotor oscillations.

The results of simulations using Model 1 and Model 2 are shown in Figure 7, $C 1$ and $D 1$, respectively. For each model, the integrated activity of all four RG centers (IRG-E, I-RG-F, r-RG-F, and r-RG-E) and all left CIN populations [I-CINe-F (V3), I-CINi-F $\left(\mathrm{VO}_{\mathrm{D}}\right)$, and I-CINe1-F $\left(\mathrm{VO}_{\mathrm{V}}\right)$ for Model 1; and I-CINe-F (V3), I-CINi-F ( $\left.\mathrm{VO}_{\mathrm{D}}\right)$, and I-CINe-E $\left(\mathrm{VO}_{\mathrm{v}}\right)$ for Model 2] are shown while the average neuronal excitation $(\alpha)$ was slowly increased. In each panel, the right $\mathrm{CIN}$ populations behaved similarly to the left ones and are not shown. In both models, increasing neuronal excitation resulted in the acceleration of rhythmic bursting with maintenance of left-right and flexorextensor alternation throughout the whole range of $\alpha$ values.

The amplitude of activity of the RG-F centers in both models initially goes up and then decreases, resembling the amplitude changes in the isolated population (Fig. 5D) as well as in experimental recordings from the flexor (L2) ventral root (Fig. 5F, 7C2,D2, middle diagrams, red curves). Analysis of the activity of the three CIN populations in the models allows evaluation of the relative contribution of each population to left-right coordination at different levels of neuronal excitation. With an increase in $\alpha$ values, the amplitude of activity of each CIN population in both models is affected by two opposing processes. On one hand, the increase of intrinsic neuronal excitation per se should increase the amplitude of each CIN activity. On the other hand, the reduction of the amplitudes of activity of RG centers providing synaptic inputs to these populations should decrease the amplitude of CIN activity.

In the inhibitory $\mathrm{V}_{\mathrm{D}} \mathrm{CIN}$ populations, the synaptic process dominates, due to the relatively low leakage conductance in these neurons in the models defining the low sensitivity of their membrane potentials to changes in $\alpha$ (imitating drug concentration). Therefore, the amplitude of their activity reduces similarly to that of the ipsilateral flexor RG centers that provide direct synaptic inputs to these populations (Fig. 7C2,D2, bottom diagrams, purple curves). As a consequence, $\mathrm{V}_{\mathrm{D}}$ populations strongly contribute to left-right alternation at low levels of excitation in the network when flexor RG output is maximal, whereas at high levels of excitation their role is significantly reduced as flexor RG amplitude decreases.

In the excitatory $\mathrm{V} 3 \mathrm{CIN}$ populations, the two opposing processes partly compensate for each other, and hence the amplitude of their activity (after an initial increase) remains relatively constant and does not depend much on $\alpha$ and oscillation frequency (Fig.7C2,D2, bottom diagrams, green curves).

The amplitudes of activity of the excitatory $\mathrm{VO}_{\mathrm{v}}$ populations (CINe1-F in Model 1 and $\mathrm{CINe}-\mathrm{E}$ in Model 2) are zero at small values of $\alpha$ and monotonically increase with $\alpha$, despite the reduction in the amplitudes of activity in the corresponding RG centers (Fig. 7C2,D2, bottom diagrams, brown curves). The increase in $\mathrm{V}_{\mathrm{v}}$ activity is due to the strong activation and recruitment of V2a neurons mediating the RG inputs to $\mathrm{VO}_{\mathrm{V}} \mathrm{CINs}$ (Fig. $7 A, B$ ). Therefore, in both models, the excitatory $\mathrm{VO}_{\mathrm{v}} \mathrm{CINs}$ contribute more strongly to left-right alternation at higher levels of $\alpha$. In Model 1, this contribution occurs because V0 $\mathrm{V}_{\mathrm{V}} \mathrm{CINs}$ inhibit the contralateral flexor centers via inhibitory interneurons (Fig. 7A). In Model 2, this contribution occurs because the $\mathrm{VO}_{V}$ CINs mediate excitation from each extensor center to the contralateral flexor center (Fig. 7B). Hence, in both of our models, both $\mathrm{V}^{2} \mathrm{a}$ and $\mathrm{VO}_{\mathrm{V}}$ populations are critically involved in providing left-right alternation at high levels of excitation and high oscillation frequencies.

In the intact models, left-right alternation is maintained at all levels of excitation (Fig. $7 C 1, D 1$ ), because the synchronizing action of $\mathrm{V} 3 \mathrm{CINs}$ is overcome by alternating the actions of $\mathrm{V} 0_{\mathrm{D}} \mathrm{CINs}$ at lower levels of excitation with those of $\mathrm{VO}_{V} \mathrm{CINs}$ at higher levels of excitation. This is illustrated in the bottom diagrams of Figure 7, C2 and D2, which show that the amplitude of V3 population activity (green) is less than the amplitude of $\mathrm{V}_{\mathrm{D}}$ population activity (purple) at low levels of $\alpha$, and less than the amplitude of $\mathrm{V}_{\mathrm{V}}$ population activity (brown) at high levels of $\alpha$.

Let us now consider how these models behave following a removal of all $\mathrm{V} O \mathrm{CIN}$ populations, only the $\mathrm{VO}_{\mathrm{V}}$ or V2a populations, or only the $\mathrm{VO}_{\mathrm{D}}$ populations (Fig. 8).

When both types of VO populations are deleted (Fig. $8 A$ ), the only remaining commissural pathways in both models are mediated by the excitatory $\mathrm{V} 3$ populations (Fig. 8A, right column, bottom diagram). In this case, V3 
A

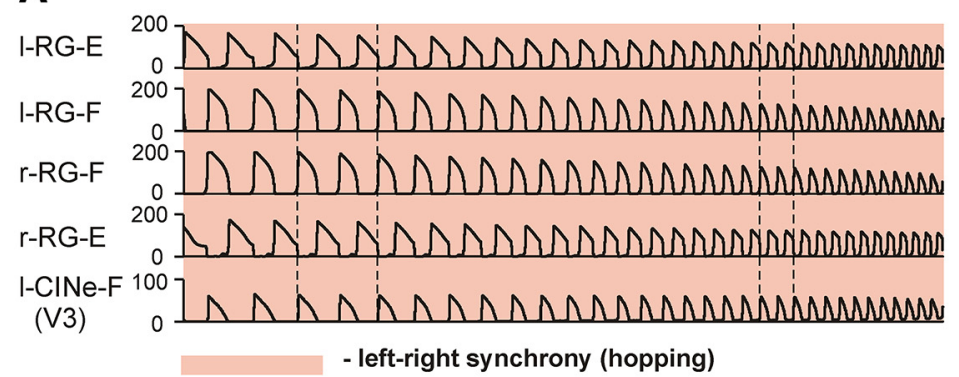

B

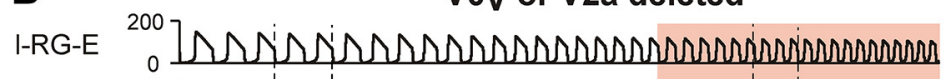

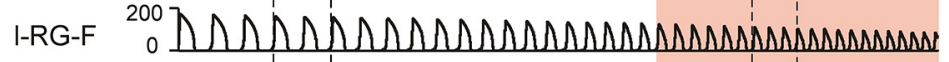

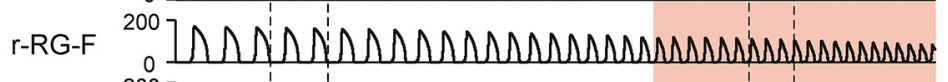

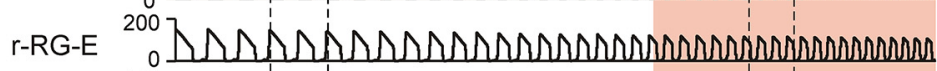

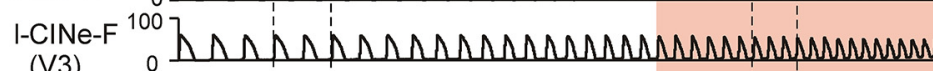

(V3)

I-CINi-F 100

(VOD)

\section{C}

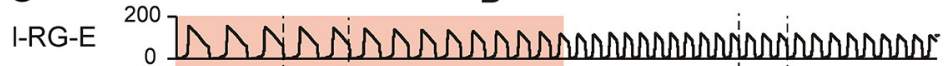

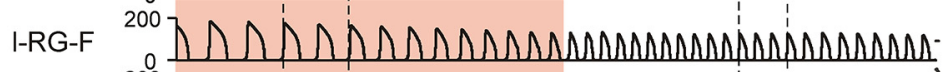

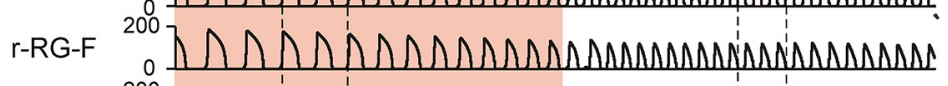

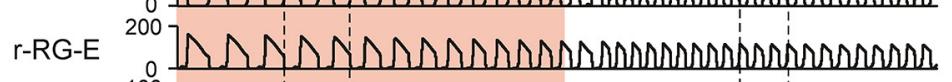

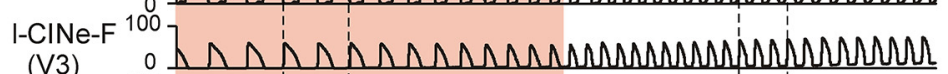

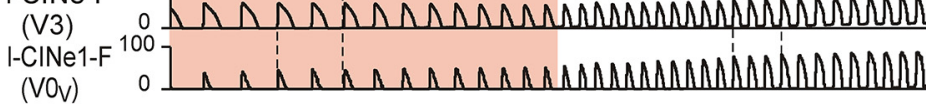

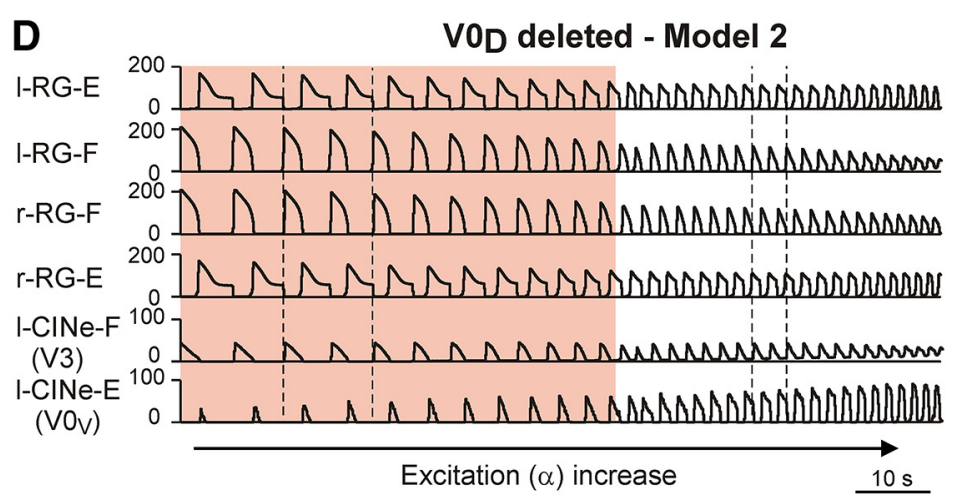

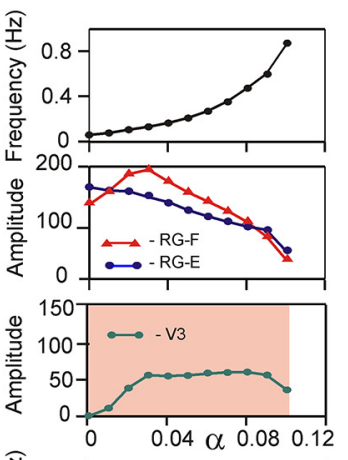
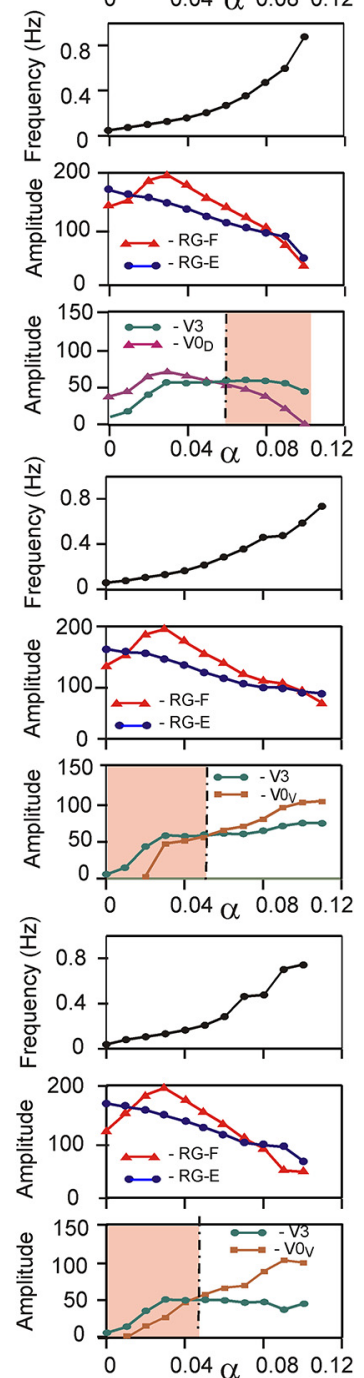

Figure 8. Frequency-dependent changes in left-right coordination of activity following selective removal of particular CIN pathways. $\boldsymbol{A}$, Performance of both models after removal of both $\mathrm{VO}\left(\mathrm{V} \mathrm{O}_{\mathrm{V}}\right.$ and $\left.\mathrm{V} \mathrm{O}_{\mathrm{D}}\right) \mathrm{CIN}$ populations. $\boldsymbol{B}$, Performance of both models after selective removal of $\mathrm{V}_{V} \mathrm{CIN}$ or $\mathrm{V} 2 \mathrm{a}$ populations. $\boldsymbol{C}, \boldsymbol{D}$, Performance of Model 1 and Model 2, respectively, after selective removal of $\mathrm{V}_{\mathrm{D}} \mathrm{CIN}$ populations. The left column in each panel shows the activity of all centers and the remaining (left) CIN populations. In all panels, $\alpha$ was increased for $200 \mathrm{~s}$. The vertical dashed lines indicate the beginning of the left flexor phases at lower and higher values of $\alpha$ (and oscillation frequency). The right column in each panel shows changes of the key model characteristics in response to a slow ramp increase of neuronal excitation: the top diagram shows changes in the frequency of oscillation; the middle diagram represents changes in the amplitude of activity of I-RG-F (red) and I-RG-E (blue) centers; and the bottom diagram shows changes in the amplitude of activity of $\mathrm{V} 3$ (green), $\mathrm{VO}_{\mathrm{D}}$ (purple), and $\mathrm{VO}_{\mathrm{V}}$ (brown) $\mathrm{CIN}$ populations. The dash-dotted vertical lines in right panels indicate transitions between left-right alternation and left-right synchronization. The regions of left-right synchronized activity are highlighted by pink rectangles. Modified from Shevtsova et al. (2015), their Figures 7 and 8, with permission. 
CINs synchronize oscillations of the left and right flexor RG populations at all levels of neuronal excitation and any locomotor frequency, resulting in a "hopping" pattern.

If only $\mathrm{V} 2 \mathrm{a}-\mathrm{V} \mathrm{V}_{\mathrm{V}}$-mediated (Fig. $8 B$ ) or only $\mathrm{V}_{\mathrm{D}^{-}}$ mediated (Fig. 8C,D) pathways are selectively deleted, the model behavior depends on the interplay between the V3-mediated left-right synchronization and the remaining V0 populations that support left-right alternation. Figure $8 B$ shows that when either the $\mathrm{V}_{\mathrm{V}}$ or the $\mathrm{V} 2 \mathrm{a}$ populations are deleted from either model, the left and right flexor RG centers, as well as the left and right extensor RG centers, exhibit alternating activity at lower values of $\alpha$ (low locomotor speeds) and synchronous activity at higher values of $\alpha$ (higher locomotor speed). The bottom diagram in the right column of Figure $8 B$ shows that the amplitude of activity of the remaining inhibitory $\mathrm{VO}_{\mathrm{D}} \mathrm{CIN}$ populations decreases with increasing $\alpha$. In contrast, the amplitude of the excitatory V $3 \mathrm{CIN}$ populations (I-CINe-F and $\mathrm{r}-\mathrm{CINe}-\mathrm{F})$ after an initial increase remains relatively constant. As a result, at some value of excitation, the activity of the $\mathrm{V} 3$ populations becomes stronger than the activity of the $\mathrm{V} 0_{\mathrm{D}}$ populations, leading to the cross-cord synchronization of activity of the left and right flexor and of the left and right extensor RG centers. In summary, removal of $\mathrm{VO}_{V} \mathrm{CIN}$ or V2a populations results in left-right alternation of neuronal activity at lower levels of neuronal excitation (low locomotor speeds) and left-right synchronization at higher levels of neuronal excitation (higher locomotor speeds).

Figure $8, C$ and $D$, demonstrates the results of simulations using Model 1 and Model 2, respectively, after removal of $\mathrm{V}_{\mathrm{D}}$ populations. In both models, left and right homonymous RG centers exhibit synchronous activity at lower values of $\alpha$ and switch to alternating activity at higher values of $\alpha$. In both models, the amplitude of activity of the $\mathrm{VO}_{\mathrm{V}} \mathrm{CIN}$ populations increases with increasing $\alpha$ (Fig. $8 C, D$, right column, bottom diagram in both) because of the dramatic increase in the activity of V2a populations exciting these $\mathrm{VO}_{\mathrm{V}} \mathrm{CIN}$ populations (Fig. $7 A, B)$. At the same time, the amplitude of the V3 CIN populations ( $\mathrm{I}-\mathrm{ClNe}-\mathrm{F}$ and $\mathrm{r}-\mathrm{CINe}-\mathrm{F}$ ) remains relatively constant. Eventually, the amplitude of activity of the $\mathrm{VO}_{\mathrm{V}}$ $\mathrm{CIN}$ populations promoting alternation becomes stronger than the amplitude of V3 CIN populations promoting synchronization. Therefore, in both our models, the removal of $\mathrm{V}_{\mathrm{D}} \mathrm{CIN}$ populations leads to left-right synchronization of neuronal activity at lower levels of neuronal excitation (low locomotor speeds) and left-right alternation at higher levels of excitation (higher locomotor speeds).

The simulation results of Shevtsova et al. (2015) described above closely reproduce the experimental data of Talpalar et al. (2013). They support the earlier suggestion that left-right alternation is provided by dual commissural pathways involving the inhibitory $\mathrm{V}_{\mathrm{D}}$ and excitatory $\mathrm{V} \mathrm{O}_{\mathrm{V}}$ $\mathrm{CINs}$, and that the contribution of the $\mathrm{V} 0_{\mathrm{D}}$ pathway to left-right alternation is dominant at low frequencies and reduces as locomotor frequency increases, whereas the contribution of the $\mathrm{V} 2 \mathrm{a}-\mathrm{V} \mathrm{O}_{\mathrm{v}}$ pathway is weak at low frequencies but is enhanced as frequency increases. The models suggest that these important features may be based on the following: (1) a relatively weak dependence of excitation of the VO CINs on neuroactive drug concentration, which leads to a net reduction of $\mathrm{VO}_{\mathrm{D}}$ activity due to the reduction in the amplitude of rhythm-generating activity when the frequency increases; and (2) a strong dependence of $\mathrm{V} 2$ a neuron activity and recruitment on the neuroactive drug concentration (Crone et al., 2009; Zhong et al., 2011); these neurons mediate input to $\mathrm{VO}_{\mathrm{V}} \mathrm{CINs}$, hence providing a net increase of their activity with frequency. A more detailed explanation of this suggestion can be found in the study by Shevtsova et al. (2015).

The two models described in this study show very similar behavior. In both models, the $\mathrm{VO}_{\mathrm{D}}$ populations receive input from the flexor $R G$ center and inhibit the contralateral flexor RG center. Based on this, our models predict that $\mathrm{V} \mathrm{O}_{\mathrm{D}} \mathrm{CINs}$ should exhibit flexor-related rhythmic activity, which can be tested in future experiments. The two models differ by the organization of $\mathrm{V} 2 \mathrm{a}-\mathrm{V} \mathrm{O}_{\mathrm{V}}$ pathways and the phase of activity of these neurons. Specifically, the $\mathrm{V} 2 \mathrm{a}-\mathrm{V} 0_{V}$ neurons may (1) coordinate left and right flexor centers via inhibitory interneurons as predicted by Model 1, (2) mediate connections from each extensor center to the contralateral flexor center as predicted by Model 2, or (3) include both of these pathways (Shevtsova et al., 2015). The choice between these models can be made in the future based on recording from $\mathrm{VO}_{\mathrm{V}}$ neurons, and may depend on whether their activity is mostly in phase with the flexors (confirming Model 1), with extensors (confirming Model 2), or with both types (confirming option 3). It is certainly possible that the two $\mathrm{V} 2 \mathrm{a}-\mathrm{V}_{\mathrm{v}}$ pathways are both present in the spinal network, because V2a neurons with both flexor- and extensorrelated rhythmic activity have been previously described (Dougherty and Kiehn, 2010; Zhong et al., 2010). Moreover, other, possibly more complicated constructions of commissural pathways, mediated by $\mathrm{V}_{\mathrm{D}}, \mathrm{V}_{\mathrm{V}}, \mathrm{V} 3 \mathrm{CINs}$, their unknown subtypes, or other CINs, could be considered and represent a subject of future studies.

\section{Axon guidance and left-right coordination: role of Netrin-1, DCC, and EphA4}

As described above, the coordination of left-right activity in the spinal cord is provided by multiple commissural pathways mediated by different CIN types, whose axons cross midline and affect neurons on the contralateral side of the cord. During spinal cord development, this process is directed by axon-guiding molecules such as Netrin-1 that bind to and activate the axonal receptor DCC (Kennedy et al., 1994; Kaprielian et al., 2001; Rabe et al., 2009; Rabe Bernhardt et al., 2012; Vallstedt and Kullander, 2013). The other axon-guidance molecule involved in the development of connectivity across the midline of the spinal cord is EphA4 (Dottori et al., 1998; Kullander et al., 2003).

Modeling of the spinal cord reorganizations following the genetic removal of axon-guidance molecules, such as Netrin-1, DCC, and EphA4 was performed by Rybak et al. (2013) using a reduced model of left and right flexor rhythm generators interacting via unnamed inhibitory and excitatory CINs involved in left-right coordination of ac- 
tivity. This model was then used by Shevtsova et al. (2015) as a basis for developing the more elaborated and complicated models that explicitly incorporated genetically identified $\mathrm{V}_{\mathrm{D}}, \mathrm{V}_{\mathrm{V}}$, and $\mathrm{V} 3 \mathrm{CINs}$ (Models 1 and 2 described in the previous section). Similar to the basic model of Rybak et al. (2013), these later models can simulate spinal circuit reorganizations following genetic removal of the above axon-guiding molecules and reproduce the corresponding experimental data (N. A. Shevtsova and I. A. Rybak, unpublished results). Below, we interpret the above circuit reorganizations using the network architecture of Model 1 (Fig. 7A), although the slightly different schematic of Model 2 could be used as well.

Netrin-1 is found in the floor plate and neuroepithelial cells of the ventral region of the spinal cord and is involved in attracting CIN axons and directing them to the contralateral side of the cord. Figure 9A2 (modified from Rabe et al., 2009, with permission) shows that the loss of Netrin-1 in the knockout (KO) mice significantly reduces the number of axons crossing the midline for $\mathrm{V}_{\mathrm{D}}$ ( $\mathrm{Lbx} 1^{-}$ $\left.\mathrm{Pax}^{+}\right)$and $\mathrm{VO}_{\mathrm{V}}\left(\mathrm{Lbx}^{-}{ }^{-} \mathrm{Pax} 2^{+}\right) \mathrm{CINs}$ without changing the number of V3 (Nkx2.2) axons crossing the midline. This reduction in the number of midline-crossing axons is shown in the model schematic in Figure $9 A 1$ by dashed lines, illustrating that, although some $\mathrm{V}_{\mathrm{D}}$ and $\mathrm{V}_{\mathrm{V}}$ connections still go to the contralateral side (as in the intact model), some of their connections stay on the ipsilateral side (Fig. 9A1, curved dashed arrows). These changes in commissural interactions should reduce mutual inhibition between left and right $R G s$ mediated by $V 0_{D}$ and $V O_{V}$ $\mathrm{CINs}$, and allow domination of the V3-mediated pathways synchronizing the activity of left and right RGs leading to a hopping pattern, similar to that in the fully Vo removed case (Fig. 8A). This shift in the left-right commissural interactions to domination by left-right excitation provides a clear explanation of the experimental data on left-right synchronous activity and hopping gate in Netrin-1 KO mice (Rabe et al., 2009; Vallstedt and Kullander, 2013).

In DCC KO mice, the number of midline-crossing axons becomes reduced for both the CIN types supporting leftright alternation: $\mathrm{VO}_{\mathrm{D}}\left(\mathrm{Lbx}^{-} 1^{-} \mathrm{Pax} 2^{+}\right)$and $\mathrm{VO}_{\mathrm{V}}\left(\mathrm{Lb} \times 1^{-}\right.$ $\mathrm{Pax} 2^{+}$), and the $\mathrm{V} 3$ (Nkx2.2) CINs promoting left-right synchrony [Fig. 9B2 (reprinted with permission from Rabe Bernhardt et al., 2012)]. This is shown in the model schematic in Figure $9 B 1$ by the dashed lines, illustrating that some of the $\mathrm{VO}_{\mathrm{D}}, \mathrm{V}_{\mathrm{V}}$ and $\mathrm{V} 3$ connections do not cross midline and stay ipsilaterally. These should strongly reduce all left-right interactions, leading to an uncoordinated left-right activity (Rybak et al., 2013). This reduction of commissural interactions that is responsible for the coordination of left and right activities provides an explanation of the experimental data on uncoordinated leftright activity in DCC KO mice (Rabe Bernhardt et al., 2012; Vallstedt and Kullander, 2013).

$E p h A 4^{+}$neurons are repelled by ephrin-B3 expressed at the midline of the spinal cord. In EphA4 KO mice, the regular left-right alternating walking pattern is replaced with a rabbit-like left-right synchronized hopping gait (Dottori et al., 1998; Kullander et al., 2003; Akay et al., 2006). It has been initially suggested that in the EphA4 KO mice, the normal left-right alternating activity, which usually results from crossed net inhibition, is overridden by the abnormal crossed excitatory interactions (Butt et al., 2005; Kiehn, 2006; Restrepo et al., 2009, Rybak et al., 2013). Studies in spinal cords isolated from EphA4 KO mice have confirmed that switching to the synchronized hopping pattern is accompanied by, and supposedly results from, an abnormal midline crossing of axons of some excitatory neurons that normally stay ipsilateral to the spinal cord (Restrepo et al., 2009). However, based on the information that V2a neurons, projecting to $\mathrm{VO}_{\mathrm{V}} \mathrm{CINs}$ (Figs. 7A,B, 9C), are EphA4 ${ }^{+}$(Lundfald et al., 2007), it is reasonable to suggest that switching to left-right synchronous hopping-like activity in EphA4 KO mice may result from a reduction of the number of $\mathrm{V} 2 \mathrm{a}$ axons projecting to the ipsilateral $\mathrm{VO}_{v} \mathrm{CINs}$, because some of these axonsdue to the lack of EphA4 molecules-cross the midline and project to the other side of the cord (Borgius et al., 2014). This redirection of $\mathrm{V} 2 \mathrm{a}$ axons in EphA4 KO mice is illustrated in Figure $9 C$ by the double dashed arrows out of V2a neurons, one of which crosses the midline. This redirection of $\mathrm{V} 2 \mathrm{a}$ axons reduces the inhibitory commissural interactions mediated by the $\mathrm{V} 2 \mathrm{a}-\mathrm{V} \mathrm{O}_{\mathrm{V}}$ pathways that secure left-right alternation in the intact mice and allows their action to be overcome by the V3 pathways, promoting left-right synchronizing, leading to the left-right synchronized hopping behavior.

\section{Flexor-extensor alternation: role of $\mathrm{V} 1$ and V2b interneurons}

Reciprocal activation of flexor and extensor muscles represents the fundamental mechanism involved in any motor behaviors, including locomotion. The spinal cord circuits providing flexor-extensor alternation have been studied recently by Zhang et al. (2014; see also Goulding et al., 2014). They have shown that the alternating flexorextensor activity during locomotion depends on two classes of ventrally located inhibitory neurons: V1 and V2b. Abrogating V1 and V2b interneuron-derived neurotransmission in the isolated spinal cord results in a synchronous pattern of flexor-related (L2) and extensorrelated (L5) locomotor activity. Mice lacking V1 and V2b inhibition are unable to move their limb joints and display marked deficits in limb-driven reflex movements.

Note that the population of V1 interneurons is composed of multiple functionally different cell types, including la inhibitory interneurons and Renshaw cells mediating different forms of inhibition at the level of motoneurons (Goulding, 2009). Here, we use the term "V1 neurons" only for the subpopulation of V1 neurons that are potentially involved in flexor-extensor and left-right interactions at the CPG (not motoneuron) level (i.e., for V1 cells not representing la or Renshaw cells).

The recent study by Zhang et al. (2014) has shown that, although both V1 and V2b interneurons are involved in flexor-extensor alternation, their functional roles are different, and their selective removal from the intact cord and isolated hemicord produces different effects on locomotor pattern. The major findings of the study by Zhang et al. (2014) are summarized as follows: (1) removal of V1 
A1

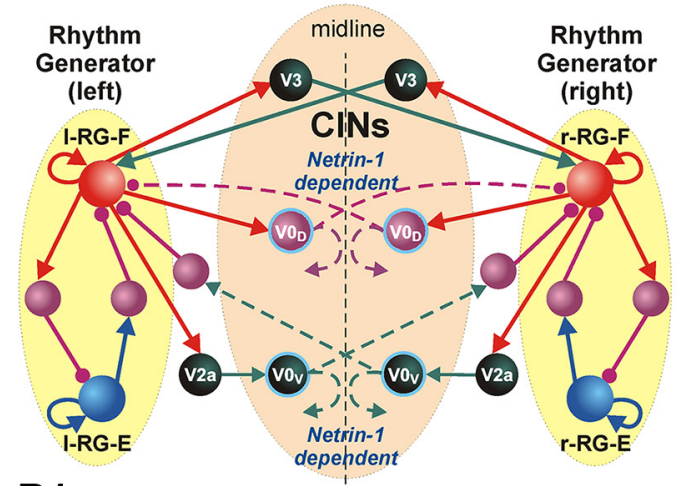

B1

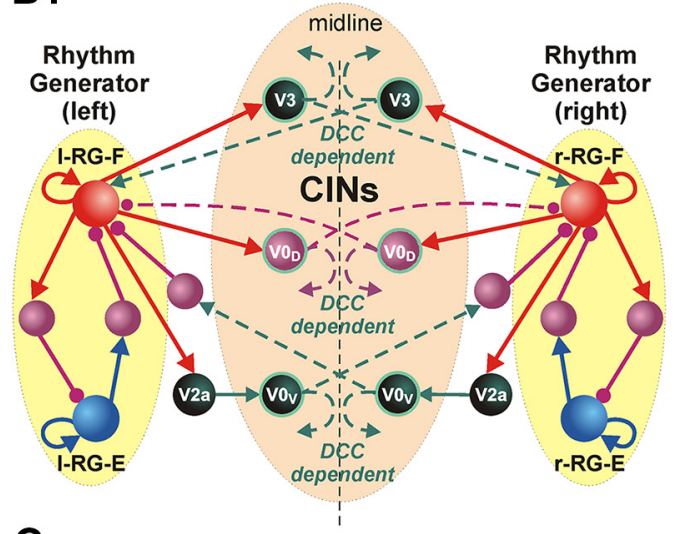

C

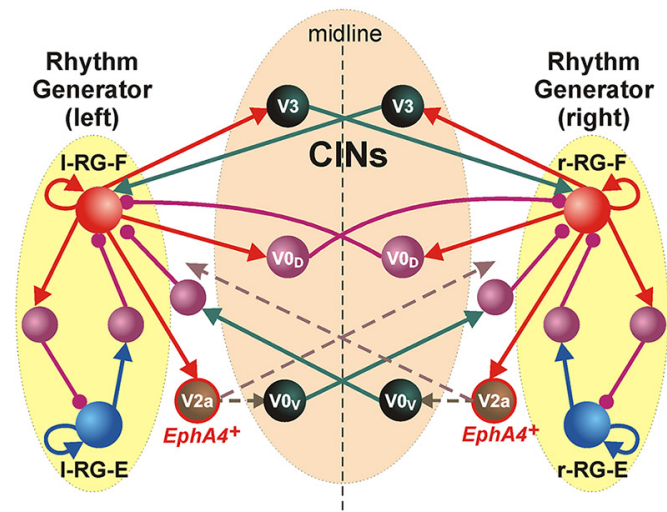

A2

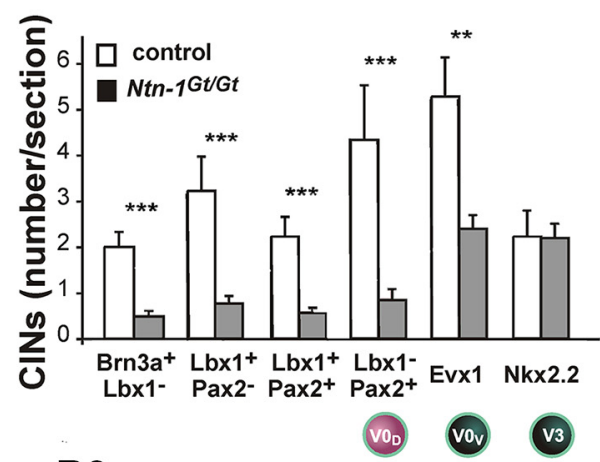

B2

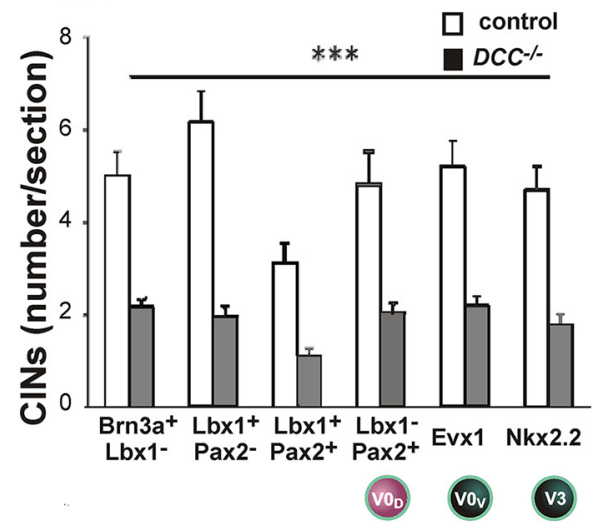

Figure 9. Potential changes in left-right coordination in models of mutants lacking particular axon-guiding molecules Netrin-1, $D C C$, or EphA4. A1, Model of circuits in Netrin-1 KO mice. The majority of axons of $\mathrm{VO}_{\mathrm{D}}$ and $\mathrm{V}_{\mathrm{V}}$ CINs do not cross the midline (dashed lines), hence reducing mutual inhibition between left and right RGs. A2, Quantification of transcription factor phenotype in different traced CINs that shows significant differences in affected $\mathrm{V}_{\mathrm{D}}$ and $\mathrm{V}_{\mathrm{V}} \mathrm{CIN}$ (but not $\mathrm{V} 3$ ) populations in $\mathrm{Netrin}-1 \mathrm{KO}$ mice. Modified from Rabe et al. (2009), their Figure 5L, with permission. B1, Model of circuits in DCC KO mice: significant portions of axons of $\mathrm{VO}_{\mathrm{D}}$ and $\mathrm{VO} \mathrm{V}_{\mathrm{V}}$, and $\mathrm{V} 3 \mathrm{CINs}$ do not cross the midline (dashed lines), hence reducing both mutual inhibition and mutual excitation between left and right RGs. B2, Quantification of transcription factor phenotype in different traced CINs that shows significant differences in affected $\mathrm{V} 0_{\mathrm{D}}, \mathrm{V} \mathrm{O}_{\mathrm{V}}$, and $\mathrm{V} 3 \mathrm{CIN}$ populations in $D C C \mathrm{KO}$ mice. Modified from Rabe Bernhardt et al. (2012), their Figure 4I, with permission. C, Model of circuits in EphA4 KO mice: many axons of EphA4 ${ }^{+}$V2a populations do not activate $\mathrm{VO}_{V} \mathrm{CINs}$, hence reducing mutual inhibition between left and right RGs. In $\boldsymbol{A 1}$, B1, and $\boldsymbol{C}$, both the right connections with reduced numbers of axons and the redirected axons in the corresponding mutant circuits are shown by dashed lines.

neurons results in a significant reduction in the frequency of drug-induced locomotor activity in the isolated intact cord (two to three times and more), which is similar to the frequency reduction observed after cord hemisection, and a lack of V1 neurons has no observed effects on the hemicord rhythmic activity; and (2) both interneuron types, V1 and V2b, secure flexor-extensor alternation in the intact cord, so that only removal/silencing of both 
A

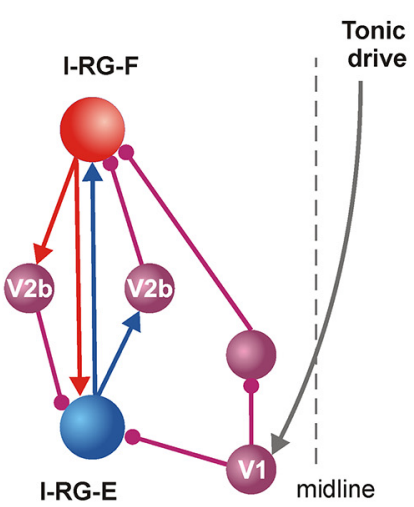

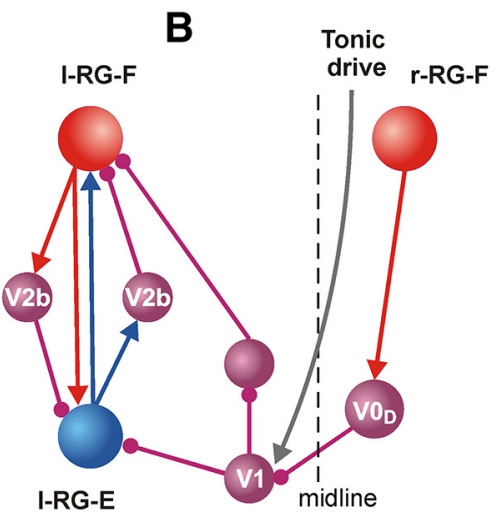

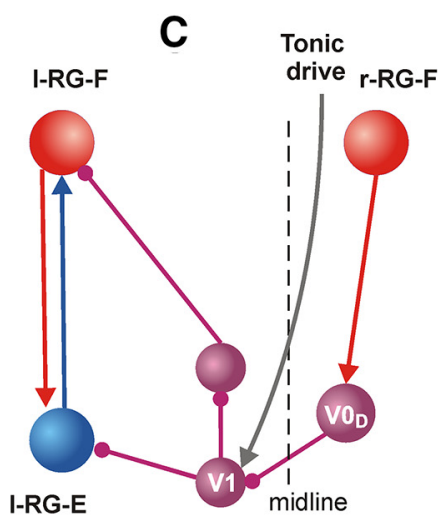

D
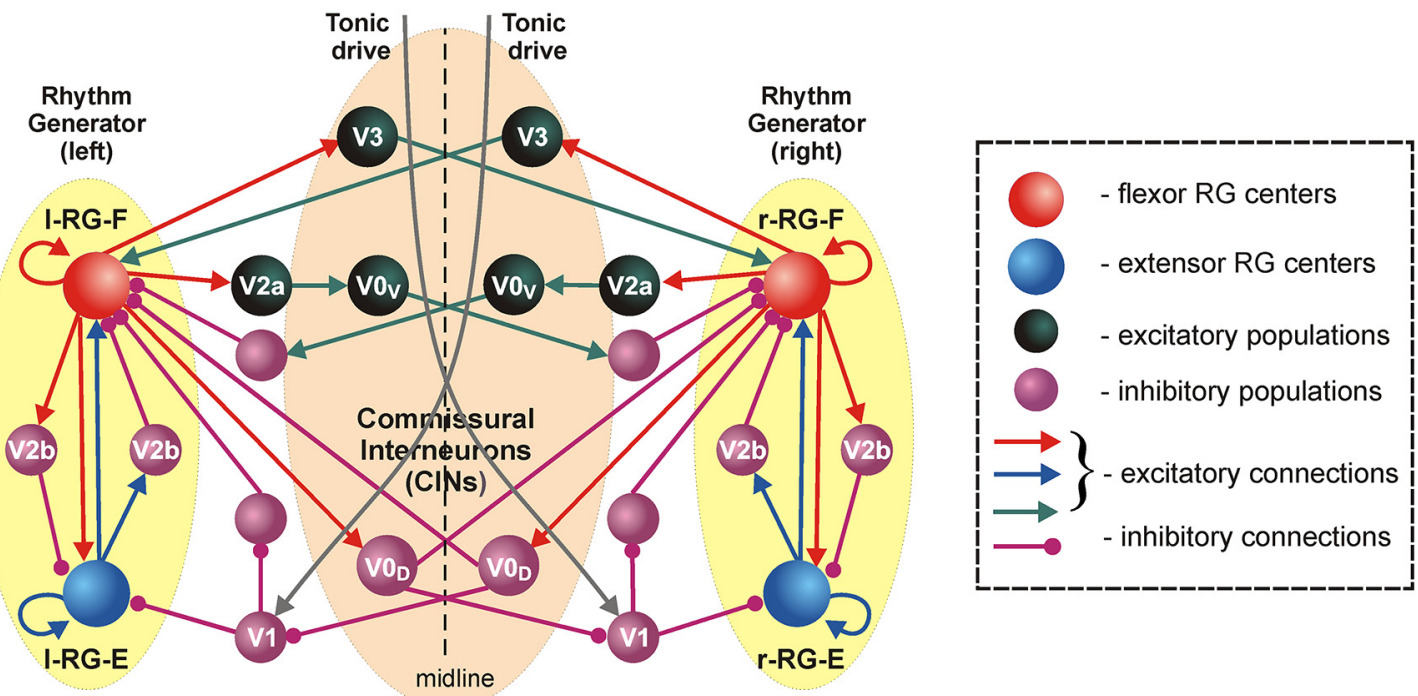

Figure 10. Role of V1 and V2b interneurons in flexor-extensor alternation. $\boldsymbol{A}, \boldsymbol{B}, \mathrm{V} 2 \mathrm{~b}$ neurons mediate mutual inhibition between flexor and extensor half-centers on each side of the cord. V1 neurons (involved in interactions between rhythm-generating centers) receive excitation from the contralateral side of the cord. This excitatory input should include tonic excitatory drive. These V1 neurons provide an additional inhibition of the ipsilateral extensor center and may disinhibit the ipsilateral flexor half-center. $\boldsymbol{B}$, The activity of the above $\mathrm{V} 1$ cells is negatively modulated (reduced) in phase with the contralateral flexor activity via inhibition from the contralateral $\mathrm{V} \mathrm{O}_{\mathrm{D}} \mathrm{CINs}$. $\boldsymbol{C}$, The above modulation of V1 neuron activity allows them to secure flexor-extensor alternation after removing V2b neurons in the intact cord. $\boldsymbol{D}$, The full schematic of bilaterally interacting rhythm generators in the spinal card with incorporated V1 and V2b circuits.

types leads to flexor-extensor synchrony. In contrast, flexor-extensor alternation in the isolated hemicord is entirely supported by V2b neurons, whose silencing results in flexor-extensor synchrony.

Based on the data from the study by Zhang et al. (2014), the following features of organization of V2b and V1 circuits involved in flexor-extensor alternation and locomotor frequency control can be hypothesized:

(1) The V2b neurons mediate mutual inhibition between flexor and extensor half-centers on each side of the cord (Fig. 10A,B).

(2) The V1 neurons (involved in interactions between rhythm-generating centers) receive excitation only from the contralateral side of the cord, and hence they should not be active and operate in isolated hemicords (i.e. after hemisection; Fig. 10A,B).

(3) The excitatory input to V1 neurons from the contralateral side of the cord includes tonic excitatory drive
(Fig. 10A-C) that maintains sustained activity of V1 neurons in the intact cord. This tonic drive can be provided by separate types of commissural interneurons that are activated by drugs in this preparation, but they are normally activated by input from the mesencephalic and cerebellar locomotor regions and send their axons to the contralateral side of the spinal cord (Jankowska and Noga, 1990; Matsuyama and Mori, 1998; Bannatyne et al., 2003; Jankowska et al., 2003, 2005).

(4) When active (in the intact cord), these V1 neurons provide an additional inhibition of the ipsilateral extensor half-center and may disinhibit the ipsilateral flexor halfcenter (Fig. 10A-C), hence allowing the generation of high locomotor frequencies in the intact cord. Therefore, re$\mathrm{moval} /$ inactivation of these neurons in the intact cord or hemisection should lead to slowing the locomotor frequency. These $\mathrm{V} 1$ neurons may also serve as targets for 
the supraspinal control of locomotor speed in the intact system (Gosgnach et al., 2006; Zhang et al., 2014).

(5) The activity of the V1 cells is negatively modulated (reduced) in phase with the contralateral flexor activity, for example via inhibition from the contralateral $\mathrm{VO}_{\mathrm{D}} \mathrm{CINs}$ (Fig. 10B,C). This rhythmic reduction of V1 inhibition in phase with contralateral flexor activity allows these neurons to secure flexor-extensor alternation after removing V2b neurons in the intact cord (Fig 10C).

Figure $10 D$ shows an updated schematic of the model of Shevtsova et al., 2015; Fig. 7A, Model 1, that incorporates the V1 and V2b circuits hypothesized above (a similar modification can be applied for Model 2). In this architecture, a removal of V1 population in the intact cord or a hemisection (which removes the contralateral excitatory drive to V1 populations) would lead to a disinhibition of extensor centers and additional inhibition of flexor centers (via a disinhibition of interposed inhibitory interneurons), leading to slowing down the locomotor oscillations. This would be consistent with point 1 above. Also in this architecture, both V2b (explicitly) and V1 populations (due to inhibitory modulation of its activity by the contralateral $\mathrm{V} \mathrm{O}_{\mathrm{D}}$ population) would secure flexor-extensor alternation in the intact cord, but only V2a populations would be able to do this after hemisection silencing V1 neurons. This would provide point 2 above.

It is expected that this united architecture will be able both to maintain all the features of the locomotor network described above and to reproduce the major findings of the study by Zhang et al. (2014) concerning the role of V1 and V2b neurons for flexor-extensor alternation and frequency control.

\section{Conclusions}

Our analysis has focused on using some logical and modeling approaches that allowed us to explicitly incorporate several known genetically identified neuron types into a hypothesized network architecture, representing a connectome of spinal circuits that includes the left and right CPGs interacting via several distinct CIN types $\left(\mathrm{VO}_{\mathrm{D}}, \mathrm{VO}_{\mathrm{V}}, \mathrm{V} 3\right)$ and ipsilaterally projecting neurons $(\mathrm{V} 1, \mathrm{~V} 2 \mathrm{a}, \mathrm{V} 2 \mathrm{~b})$. We realize that other, currently unknown classes of spinal interneurons with different properties and connectivity patterns can be found in the future, and that some of the currently identified classes can be subdivided into functionally different subclasses. Nevertheless, we believe that the network architectures considered here could serve as a basis for future, more elaborated models of the spinal circuits. These network architectures propose plausible explanations for multiple experimental data obtained in different laboratories under different experimental conditions. The predictions of this study include the following: (1) flexor-extensor asymmetry in the organization of rhythm-generating locomotor network; (2) organization and frequency-dependent interactions of commissural pathways supporting left-right alternation $\left(\mathrm{VO}_{\mathrm{D}}\right.$, $\mathrm{V} 2 \mathrm{a} / \mathrm{VO}_{\mathrm{v}}, \mathrm{V} 3$ ) and synchronization (V3) of spinal cord activity, which are potentially involved in locomotor gait control; and (3) organization of circuits of ipsilaterally projecting V1 and V2b neurons providing flexor-extensor alteration and locomotor frequency control. These predictions provide important insights into the organization of spinal locomotor CPGs and neural control of locomotion, and await experimental testing and validation.

\section{References}

Akay T, Acharya HJ, Fouad K, Pearson KG (2006) Behavioral and electromyographic characterization of mice lacking EphA4 receptors. J Neurophysiol 96:642-651. CrossRef Medline

Al-Mosawie A, Wilson JM, Brownstone RM (2007) Heterogeneity of V2-derived interneurons in the adult mouse spinal cord. Eur $\mathrm{J}$ Neurosci 26:3003-3015. CrossRef Medline

Bannatyne BA, Edgley SA, Hammar I, Jankowska E, Maxwell DJ (2003) Networks of inhibitory and excitatory commissural interneurons mediating crossed reticulospinal actions. Eur $\mathrm{J}$ Neurosci 18:2273-2284. Medline

Borgius L, Nishimaru, H, Caldeira V, Kunugise Y, Löw P, Reig R, Itohara S, Iwasato T, Kiehn O (2014) Spinal glutamatergic neurons defined by EphA4 signaling are essential components of normal locomotor circuits. J Neurosci 34:3841-3853. CrossRef Medline

Brocard F, Tazerart S, Vinay L (2010) Do pacemakers drive the central pattern generator for locomotion in mammals? Neuroscientist 16:139-155. CrossRef Medline

Brocard F, Shevtsova NA, Bouhadfane M, Tazerart S, Heinemann U, Rybak IA, Vinay L (2013) Activity-dependent changes in extracellular $\mathrm{Ca}^{2+}$ and $\mathrm{K}^{+}$reveal pacemakers in the spinal locomotorrelated network. Neuron 77:1047-1054. CrossRef Medline

Butera RJ, Rinzel JR, Smith JC (1999) Models of respiratory rhythm generation in the pre-Bötzinger complex: II. Populations of coupled pacemaker neurons. J Neurophysiol 82:398-415.

Butt SJ, Kiehn O (2003) Functional identification of interneurons responsible for left-right coordination of hindlimbs in mammals. Neuron 38:953-963. Medline

Butt SJ, Lundfald L, Kiehn O (2005) EphA4 defines a class of excitatory locomotor-related interneurons. Proc Natl Acad Sci U S A 102:14098-14103. CrossRef Medline

Crone SA, Quinlan KA, Zagoraiou L, Droho S, Restrepo CE, Lundfald L, Endo T, Setlak J, Jessell TM, Kiehn O, Sharma K (2008) Genetic ablation of V2a ipsilateral interneurons disrupts left-right locomotor coordination in mammalian spinal cord. Neuron 60:70-83. CrossRef Medline

Crone SA, Zhong G, Harris-Warrick R, Sharma K (2009) In mice lacking $\mathrm{V} 2 \mathrm{a}$ interneurons, gait depends on speed of locomotion. $\mathrm{J}$ Neurosci 29:7098-7109. CrossRef

Cymbalyuk GS, Gaudry Q, Masino MA, Calabrese RL (2002) Bursting in leech heart interneurons: cell-autonomous and network-based mechanisms. J Neurosci 22:10580-10592. Medline

Dottori M, Hartley L, Galea M, Paxinos G, Polizzotto M, Kilpatrick T, Bartlett PF, Murphy M, Köntgen F, Boyd AW (1998) EphA4 (Sek1) receptor tyrosine kinase is required for the development of the corticospinal tract. Proc Natl Acad Sci U S A 95:13248-13253. Medline

Dougherty KJ, Kiehn O (2010) Functional organization of V2a-related locomotor circuits in the rodent spinal cord. Ann N Y Acad Sci 1198:85-93. CrossRef Medline

Dougherty KJ, Zagoraiou L, Satoh D, Rozani I, Doobar S, Arber S, Jessell TM, Kiehn O (2013) Locomotor rhythm generation linked to the output of spinal shox2 excitatory interneurons. Neuron 80:920933. CrossRef Medline

Duysens J (1977) Reflex control of locomotion as revealed by stimulation of cutaneous afferents in spontaneously walking premammillary cats. J Neurophysiol 40:737-751. Medline

Duysens J, De Groote F, Jonkers I (2013) The flexion synergy, mother of all synergies and father of new models of gait. Front Comput Neurosci 7;14. CrossRef Medline

Dyck J, Lanuza GM, Gosgnach S (2012) Functional characterization of dl6 interneurons in the neonatal mouse spinal cord. J Neurophysiol 107:3256-3266. CrossRef Medline

Frigon A, Gossard JP (2009) Asymmetric control of cycle period by the spinal locomotor rhythm genera-tor in the adult cat. J Physiol 587:4617-4628. CrossRef Medline 
Gosgnach S (2011) The role of genetically-defined interneurons in generating the mammalian locomotor rhythm. Integr Comp Biol 51:903-912. CrossRef Medline

Gosgnach S, Lanuza GM, Butt SJ, Saueressig H, Zhang Y, Velasquez T, Riethmacher D, Callaway EM, Kiehn O, Goulding M (2006) V1 spinal neurons regulate the speed of vertebrate locomotor outputs. Nature 440:215-219. CrossRef Medline

Goulding M (2009) Circuits controlling vertebrate locomotion: moving in a new direction. Nat Rev Neurosci 10:507-518. CrossRef Medline

Goulding M, Bourane S, Garcia-Campmany L, Dalet A, Koch S (2014) Inhibition downunder: an update from the spinal cord. Curr Opin Neurobiol 26:161-166. CrossRef Medline

Graham Brown T (1914) On the nature of the fundamental activity of the nervous centres; together with an analysis of the conditioning of rhythmic activity in progression, and a theory of the evolution of function in the nervous system. J Physiol 48:18-46. CrossRef

Grillner S (1981) Control of locomotion in bipeds, tetrapods, and fish. In: Handbook of physiology. the nervous system; motor control (Brookhart JM, Mountcastle VB, eds), vol II, pp 1179-1236. Bethesda, MD: American Physiological Society.

Grillner S (2006) Biological pattern generation: the cellular and computational logic of networks in motion. Neuron 52:751-766. CrossRef Medline

Grillner S, Manira AE (2015) The intrinsic operation of the networks that make us locomote. Curr Opin Neurobiol 31:244-249. CrossRef Medline

Grillner S, Kozlov A, Dario P, Stefanini C, Menciassi A, Lansner A, Hellgren KJ (2007) Modeling a vertebrate motor system: pattern generation, steering and control of body orientation. Prog Brain Res 165:221-234. CrossRef Medline

Hägglund M, Dougherty KJ, Borgius L, Itohara S, Iwasato T, Kiehn O (2013) Optogenetic dissection reveals multiple rhythmogenic modules underlying locomotion. Proc Natl Acad Sci U S A 110:1158911594. CrossRef Medline

Halbertsma JM (1983) The stride cycle of the cat: the modelling of locomotion by computerized analysis of automatic recordings. Acta Physiol Scand Suppl 521:1-75. Medline

Hinckley CA, Ziskind-Conhaim L (2006) Electrical coupling between locomotor-related excitatory interneurons in the mammalian spinal cord. J Neurosci 26:8477-8483. CrossRef Medline

ljspeert AJ (2001) A connectionist central pattern generator for the aquatic and terrestrial gaits of a simulated salamander. Biol Cybern 84:331-348. Medline

Jankowska E (2008) Spinal interneuronal networks in the cat: elementary components. Brain Res Rev 57:46-55. CrossRef Medline

Jankowska E, Noga BR (1990) Contralaterally projecting lamina VIII interneurones in middle lumbar segments in the cat. Brain Res 535:327-333. Medline

Jankowska E, Jukes MGM, Lund S, Lundberg A (1967a) The effect of DOPA on the spinal cord. 5. Reciprocal organization of pathways transmitting excitatory action to alpha motoneurones of flexors and extensors. Acta Physiol Scand 70:369-388. CrossRef Medline

Jankowska E, Jukes MGM, Lund S, Lundberg A (1967b) The effect of DOPA on the spinal cord. 6. Half-centre organization of interneurones transmitting effects from the flexor reflex afferents. Acta Physiol Scand 70:389-402. CrossRef Medline

Jankowska E, Hammar I, Slawinska U, Maleszak K, Edgley SA (2003) Neuronal basis of crossed actions from the reticular formation on feline hindlimb motoneurons. J Neurosci 23:1867-1878. Medline

Jankowska E, Edgley SA, Krutki P, Hammar I (2005) Functional differentiation and organization of feline midlumbar commissural interneurones. J Physiol 565:645-658 CrossRef Medline

Jasinski PE, Molkov YI, Shevtsova NA, Smith JC, Rybak IA (2013) Sodium and calcium mechanisms of rhythmic bursting in excitatory neural networks of the pre-Bötzinger complex: a computational modelling study. Eur J Neurosci 37:212-230. CrossRef Medline
Jessell TM (2000) Neuronal specification in the spinal cord: inductive signals and transcriptional codes. Nat Rev Genet 1:20-29. CrossRef Medline

Kaprielian Z, Runko E, Imondi R (2001) Axon guidance at the midline choice point. Dev Dyn 221:154-181. CrossRef Medline

Kennedy TE, Serafini T, de la Torre JR, Tessier-Lavigne M (1994) Netrins are diffusible chemotropic factors for commissural axons in the embryonic spinal cord. Cell 78:425-435. Medline

Kiehn O (2006) Locomotor circuits in the mammalian spinal cord. Annu Rev Neurosci 29:279-306. CrossRef Medline

Kiehn O (2011) Development and functional organization of spinal locomotor circuits. Curr Opin Neurobiol 21:100-109. CrossRef Medline

Kiehn O, Butt SJ (2003) Physiological, anatomical and genetic identification of CPG neurons in the developing mammalian spinal cord. Prog Neurobiol 70:347-361. Medline

Kiehn O, Dougherty KJ (2013) Locomotion: circuits and physiology. In: Neuroscience in the 21st century (Pfaff DW, ed), pp 1209-1236. New York, NY: Springer.

Kjaerulff O, Kiehn O (1997) Crossed rhythmic synaptic input to motoneurons during selective activation of the contralateral spinal locomotor network. J Neurosci 17:9433-9447. Medline

Kullander K, Butt SJ, Lebret JM, Lundfald L, Restrepo CE, Rydström A, Klein R, Kiehn O (2003) Role of EphA4 and EphrinB3 in local neuronal circuits that control walking. Science 299:1889-1892. CrossRef Medline

Kwan AC, Dietz SB, Webb WW, Harris-Warrick RM (2009) Activity of $\mathrm{Hb} 9$ interneurons during fictive locomotion in mouse spinal cord. $J$ Neurosci 29:11601-11613. CrossRef Medline

Lansner A, Kotaleski JH, Grillner S (1998) Modeling of the spinal neuronal circuitry underlying locomotion in a lower vertebrate. Ann N Y Acad Sci 860:239-49. Medline

Lanuza GM, Gosgnach S, Pierani A, Jessell TM, Goulding M (2004) Genetic identification of spinal interneurons that coordinate leftright locomotor activity necessary for walking movements. Neuron 42:375-386. Medline

Lundberg A (1981) Half-centres revisited. In: Regulatory functions of the CNS. Motion and organization principles (Szentagothai J, Palkovits M, Hamori J, eds), pp 155-167. Budapest, Hungary: Pergamon Akadem Kiado.

Lundfald L, Restrepo CE, Butt SJ, Peng CY, Droho S, Endo T, Zeilhofer HU, Sharma K, Kiehn O (2007) Phenotype of V2-derived interneurons and their relationship to the axon guidance molecule EphA4 in the developing mouse spinal cord. Eur J Neurosci 26: 2989-3002. CrossRef Medline

Machado TA, Pnevmatikakis E, Paninski L, Jessell TM, Miri M (2015) Primacy of flexor locomotor pattern revealed by ancestral reversion of motor neuron identity. Cell 162:338-350. CrossRef Medline

Markin SN, Lemay MA, Prilutsky BI, Rybak IA (2012) Motoneuronal and muscle synergies involved in cat hindlimb control during fictive and real locomotion: a comparison study. J Neurophysiol 107: 2057-2071. CrossRef Medline

Matsuyama K, Mori S (1998) Lumbar interneurons involved in the generation of fictive locomotion in cats. Ann N Y Acad Sci 860: 441-443. Medline

McCrea DA, Rybak IA (2007) Modeling the mammalian locomotor CPG: insights from mistakes and perturbations. Prog Brain Res 165:235-253. CrossRef Medline

McCrea DA, Rybak IA (2008) Organization of mammalian locomotor rhythm and pattern generation. Brain Res Rev 57:134-146. CrossRef Medline

McLean DL, Dougherty KJ (2015) Peeling back the layers of locomotor control in the spinal cord. Curr Opin Neurobiol 33:63-70. CrossRef Medline

Molkov YI, Bacak BJ, Talpalar AE, Rybak IA (2015) Mechanisms of left-right coordination in Mammalian locomotor pattern generation circuits: a mathematical modeling view. PLoS Comput Biol 11: e1004270. CrossRef Medline

Orlovsky GN, Deliagina TG, Grillner S (1999) Neuronal control of locomotion. New York: Oxford UP. 
Pearson KG, Duysens J (1976) Function of segmental reflexes in the control of stepping in cockroaches and cats. In: Neural control of locomotion (Herman RM, Grillner S, Stein PSG, Stuart DG, eds), pp 519-537. New York, NY: Plenum.

Pierani A, Moran-Rivard L, Sunshine MJ, Littman DR, Goulding M, Jessell TM (2001) Control of interneuron fate in the developing spinal cord by the progenitor homeodomain protein Dbx1. Neuron 29:367-384. Medline

Quinlan KA, Kiehn O (2007) Segmental, synaptic actions of commissural interneurons in the mouse spinal cord. J Neurosci 27:65216530. CrossRef Medline

Rabe Bernhardt N, Memic F, Gezelius H, Thiebes AL, Vallstedt A, Kullander K (2012) DCC mediated axon guidance of spinal interneurons is essential for normal locomotor central pattern generator function. Dev Biol 366:279-289. CrossRef Medline

Rabe N, Gezelius H, Vallstedt A, Memic F, Kullander K (2009) Netrin-1- dependent spinal interneuron subtypes are required for the formation of left- right alternating locomotor circuitry. J Neurosci 29:15642-15649. CrossRef Medline

Restrepo CE, Lundfald L, Szabó G, Erdélyi F, Zeilhofer HU, Glover JC, Kiehn O (2009) Transmitter-phenotypes of commissural interneurons in the lumbar spinal cord of newborn mice. J Comp Neurol 517:177-192. CrossRef Medline

Rossignol S (1996) Neural control of stereotypic limb movements. In: Handbook of physiology, Sect. 12: exercise: regulation and integration of multiple systems (Rowell LB, Shepherd J, eds), pp 173-216. Bethesda, MD: American Physiological Society.

Rybak IA (2014) Vertebrate pattern generation: overview. In: Encyclopedia of Computational Neuroscience (Jaeger D, Jung R, eds.), pp 1-13. New York, NY: Springer.

Rybak IA, Shevtsova NA, St-John WM, Paton JF, Pierrefiche O (2003) Endogenous rhythm generation in the pre-Bötzinger complex and ionic currents: modelling and in vitro studies. Eur $\mathrm{J}$ Neurosci 18:239-257. Medline

Rybak IA, Shevtsova NA, Ptak K, McCrimmon DR (2004) Intrinsic bursting activity in the pre-Bötzinger complex: role of persistent sodium and potassium currents. Biol Cyber 90:59-74. CrossRef Medline

Rybak IA, Shevtsova NA, Lafreniere-Roula M, McCrea DA (2006a) Modelling spinal circuitry involved in locomotor pattern generation: insights from deletions during fictive locomotion. J Physiol 577: 617-639. CrossRef Medline

Rybak IA, Stecina K, Shevtsova NA, McCrea DA (2006b) Modelling spinal circuitry involved in locomotor pattern generation: insights from the effects of afferent stimulation. J Physiol 577:641-658.

Rybak IA, Shevtsova NA, Kiehn O (2013) Modelling genetic reorganization in the mouse spinal cord affecting left-right coordination during locomotion. J Physiol 591:5491-5508. CrossRef Medline

Rybak IA, Molkov YI, Jasinski PE, Shevtsova NA, Smith JC (2014). Rhythmic bursting in the pre-Bötzinger complex: mechanisms and models. Prog Brain Res 209:1-25. CrossRef Medline

Sherwood WE, Harris-Warrick R, Guckenheimer J (2011) Synaptic patterning of left-right alternation in a computational model of the rodent hindlimb central pattern generator. J Comput Neurosci 30:323-360. CrossRef Medline

Shevtsova NA, Talpalar AE, Markin SN, Harris-Warrick RM, Kiehn O, Rybak IA (2015) Organization of left-right coordination of neuronal activity in the mammalian spinal cord: insights from computational modelling. J Physiol 593:2403-2426. CrossRef Medline

Smith JC, Butera RJ, Koshiya N, Del Negro C, Wilson CG, Johnson SM (2000) Respiratory rhythm generation in neonatal and adult mammals: the hybrid pacemaker-network model. Respir Physiol 122:131-147. Medline
Stuart DG, Hultborn H (2008) Thomas Graham Brown (1882-1965), Anders Lundberg (1920-), and the neural control of stepping. Brain Res Rev 59:74-95. CrossRef Medline

Talpalar AE, Kiehn O (2010) Glutamatergic mechanisms for speed control and network operation in the rodent locomotor CPG. Front Neural Circuits 4:3. CrossRef Medline

Talpalar AE, Bouvier J, Borgius L, Fortin G, Pierani A, Kiehn O (2013) Dual-mode operation of neuronal networks involved in left-right alternation. Nature 500:85-88. CrossRef Medline

Tazerart S, Viemari J-C, Darbon P, Vinay L, Brocard F (2007) Contribution of persistent sodium current to locomotor pattern generation in neonatal rats. J Neurophysiol 98:613-628. CrossRef Medline

Tazerart S, Vinay L, Brocard F (2008) The persistent sodium current generates pacemaker activities in the central pattern generator for locomotion and regulates the locomotor rhythm. J Neurosci 28: 8577-8589. CrossRef Medline

Vallstedt A, Kullander K (2013) Dorsally derived spinal interneurons in locomotor circuits. Ann N Y Acad Sci 1279:32-42. CrossRef Medline

Wiggin TD, Anderson TM, Eian J, Peck JH, Masino MA (2012) Episodic swimming in the larval zebrafish is generated by a spatially distributed spinal network with modular functional organization. J Neurophysiol 108:925-934. CrossRef Medline

Wilson JM, Hartley R, Maxwell DJ, Todd AJ, Lieberam I, Kaltschmidt JA, Yoshida Y, Jessell T. M, Brownstone RM (2005) Conditional rhythmicity of ventral spinal interneurons defined by expression of the Hb9 homeodomain protein. J Neurosci 25:5710-5719. CrossRef Medline

Wolf E, Soffe S, Roberts A (2009) Longitudinal neuronal organization and coordination in a simple vertebrate: a continuous, semiquantitative computer model of the central pattern generator for swimming in young frog tadpoles. J Comput Neurosci 27:291-308. CrossRef

Zhang Y, Narayan S, Geiman E, Lanuza GM, Velasquez T, Shanks B, Akay T, Dyck J, Pearson K, Gosgnach S, Fan CM, Goulding M (2008) V3 spinal neurons establish a robust and balanced locomotor rhythm during walking. Neuron 60:84-96. CrossRef Medline

Zhang J, Lanuza GM, Britz O, Wang Z, Siembab VC, Zhang Y, Velasquez T, Alvarez FJ, Frank E, Goulding M (2014) V1 and V2b interneurons secure the alternating flexor-extensor motor activity mice require for limbed locomotion. Neuron 82:138-150. CrossRef Medline

Zhong G, Masino MA, Harris-Warrick RM (2007) Persistent sodium currents participate in fictive locomotion generation in neonatal mouse spinal cord. J Neurosci 27:4507-4518. CrossRef Medline

Zhong G, Droho S, Crone SA, Dietz S, Kwan AC, Webb WW, Sharma K, Harris-Warrick RM (2010) Electrophysiological characterization of $\mathrm{V} 2 \mathrm{a}$ interneurons and their locomotor-related activity in the neonatal mouse spinal cord. J Neurosci 30:170-182. CrossRef Medline

Zhong G, Sharma K, Harris-Warrick RM (2011) Frequencydependent recruitment of V2a interneurons during fictive locomotion in the mouse spinal cord. Nat Commun 2:274. CrossRef Medline

Zhong G, Shevtsova NA, Rybak IA, Harris-Warrick RM (2012) Neuronal activity in the isolated mouse spinal cord during spontaneous deletions in fictive locomotion: insights into locomotor central pattern generator organization. J Physiol 590:4735-4759. CrossRef Medline

Ziskind-Conhaim L, Wu L, Wiesner EP (2008) Persistent sodium current contributes to induced voltage oscillations in locomotorrelated $\mathrm{Hb} 9$ interneurons in the mouse spinal cord. J Neurophysiol 100:2254-2264. CrossRef Medline 